OPEN ACCESS

Edited by:

Liana Fattore,

Italian National Research Council, Italy

Reviewed by:

Manoel Jorge Nobre,

University of São Paulo, Brazil

Marco Venniro,

National Institute on Drug Abuse

(NIDA), United States

*Correspondence:

Timm Rosburg

timm.rosburg@upkbs.ch

Received: 12 September 2018 Accepted: 27 November 2018 Published: 11 December 2018

Citation:

Rosburg T and Schmidt A (2018)

Potential Mechanisms for the Ketamine-Induced Reduction of P3b Amplitudes.

Front. Behav. Neurosci. 12:308. doi: 10.3389/fnbeh.2018.00308

\section{Potential Mechanisms for the Ketamine-Induced Reduction of P3b Amplitudes}

\author{
Timm Rosburg ${ }^{1 *}$ and André Schmidt ${ }^{2}$ \\ ${ }^{1}$ Forensic Department, University Psychiatric Clinics Basel, Basel, Switzerland, ${ }^{2}$ Department of Psychiatry, University \\ Psychiatric Clinics Basel, Basel, Switzerland
}

In specific dosages, the N-methyl-D-aspartate receptor (NMDA) antagonist ketamine can be used to model transient psychotic symptoms in healthy individuals that resemble those of schizophrenia. Ketamine administration also temporarily impairs cognitive functions, which can be studied by event-related potentials (ERPs). ERPs also allow dissecting what stages of information processing are affected by ketamine and what stages remain functional. For tasks requiring the differentiation of targets and non-targets, it has repeatedly been shown that ketamine administration in healthy individuals leads to decreased amplitudes of the ERP component P3b in response to target stimuli. However, it could be argued that this ketamine-induced P3b reduction is the consequence of an increased difficulty to differentiate targets from non-targets, primarily mediated by ketamine's psychotomimetic rather than pharmacological effects. The current review of ERP studies seeks to clarify the issue whether P3b effects of ketamine may indeed be explained as the consequence of an experienced increase in task difficulty or whether alternative mechanisms are perhaps more plausible. The review first summarizes the effects of task difficulty on ERP components related to intentional stimulus categorization (P3b), involuntary attention switches to distractors (P3a), as well as sensory processing (P1, N1). Secondly, the ERP effects of task difficulty are contrasted with those observed in ketamine studies in healthy individuals. Findings show that P3b amplitudes are consistently diminished by an increased task difficulty, as well as after ketamine administration. In contrast and as most important difference, increased task difficulty leads to increased P3a amplitudes to distractors presented in same modality as targets, whereas ketamine leads to reduced P3a amplitudes for such distractors. This dissociation indicates that the decreased P3b amplitudes after ketamine cannot be explained by a drug-induced increase in task difficulty. The conjoint reductions of P3a and P3b amplitudes instead suggest that working memory operations, in particular working memory updating are impaired after ketamine, which is in line with previous behavioral findings.

Keywords: Schizophrenia, event-related potentials, ketamine, task difficulty, working memory, N-methyl-Daspartate, model psychosis 


\section{INTRODUCTION}

Various studies have administered subanesthetic doses of ketamine, an N-methyl-D-aspartate receptor (NMDA) antagonist, to model psychotic symptoms and psychosislike experiences in healthy individuals. Krystal et al. (1994) were one of the first research groups who experimentally investigated these effects. They used a bolus of either $0.1 \mathrm{mg}$ or $0.5 \mathrm{mg}$ ketamine/kg body weight in a placebo-controlled, double-blind design. The bolus of $0.5 \mathrm{mg} / \mathrm{kg}$ temporarily evoked pronounced negative and positive symptoms and also resulted in a range of short-lasting cognitive impairments, whereas the bolus of 0.1 $\mathrm{mg} / \mathrm{kg}$ had hardly any effect. Subsequent studies that aimed at eliciting psychotomimetic effects usually applied a single bolus of $0.1-0.3 \mathrm{mg} / \mathrm{kg}$, followed by a continuous injection of $0.135-0.9$ $\mathrm{mg} / \mathrm{kg}$ per hour to ensure a lasting drug effect (Breier et al., 1997; Adler et al., 1998; van Berckel et al., 1998; Newcomer et al., 1999; Oranje et al., 2000, 2009; Umbricht et al., 2000; Vollenweider et al., 2000; Ahn et al., 2003; Boeijinga et al., 2007; Heekeren et al., 2008; Watson et al., 2009; Musso et al., 2011; Ebert et al., 2012; Gunduz-Bruce et al., 2012; Schmidt et al., 2012, 2013; Mathalon et al., 2014; Koychev et al., 2017).

Some of the studies used event-related potentials (ERPs) in order to test whether such subanesthetic doses of ketamine lead to processing deficits in healthy individuals similar to those observed in patients with schizophrenia and to reveal the neurocognitive consequence of the drug administration (van Berckel et al., 1998; Oranje et al., 2000, 2009; Umbricht et al., 2000; Kreitschmann-Andermahr et al., 2001; Ahn et al., 2003; Boeijinga et al., 2007; Heekeren et al., 2008; Watson et al., 2009; Musso et al., 2011; Gunduz-Bruce et al., 2012; Schmidt et al., 2012, 2013; Mathalon et al., 2014; Koychev et al., 2017). In many of these ERP studies, ketamine effects were investigated in passive and active oddball experiments. The very same stimulation protocol might be used for both active and passive conditions, with only varying in instruction (Figure 1).

Two-stimulus oddball paradigms are quite commonly used. In this type of paradigm, there is one frequently and one rarely presented stimulus. In active oddball tasks, the rare stimulus is defined as target, which the participant has to identify by button press or another active response, whereas the second, frequently presented non-target stimulus requires no response (Duncan et al., 2009). The participant's identification of targets is associated with a large centro-parietal positive ERP component, the P3b, peaking $\sim 250-500 \mathrm{~ms}$ after the stimulus target onset (Glossary). In passive 2-stimulus oddball experiments, participants are instructed to ignore all stimuli and often perform an active task in a second modality, like reading a book or watching a silent video, to make sure that the attention is directed away from the to-be-ignored stimuli. In passive 2-stimulus oddball experiments, the frequently presented stimulus is designated as standard and the rare stimulus as deviant. Auditory deviants in an otherwise uniform stimulation elicit the mismatch negativity ( $\mathrm{MMN}$ ), a fronto-central negativity peaking $\sim 100$ to $250 \mathrm{~ms}$ after stimulus onset, as first described by Näätänen et al. (1978). As the MMN is elicited even when individuals ignore the auditory stimulation, the component is considered to reflect pre-attentive memory-based changedetection mechanisms (Näätänen et al., 2011, Glossary).

Ketamine leads to an attenuation of the MMN amplitude (for review Rosburg and Kreitschmann-Andermahr, 2016), which parallels findings obtained in schizophrenia (for review Erickson et al., 2016). The similarity between the behavioral effects of NMDA receptor antagonists in healthy individuals and impairments/symptoms observed in schizophrenia (including the reduced $\mathrm{MMN}$ ) provided support for the hypothesis that deficits in glutamatergic neurotransmission play a pivotal role in schizophrenia (Kantrowitz and Javitt, 2012). Besides the ketamine-induced deficit in pre-attentive deviance detection as indexed by the reduced MMN, ketamine administration in healthy subjects also diminishes the P3b amplitude, elicited by actively to-be-identified targets (e.g., Gunduz-Bruce et al., 2012; Mathalon et al., 2014). Similar to the impaired generation of the MMN, reduced P3b amplitudes, in particular to auditory stimuli, represent another consistent ERP finding in schizophrenia research and are considered as a potential biomarker for schizophrenia (Bramon et al., 2004; Thibaut et al., 2015; Earls et al., 2016).

The P3b is considered to reflect the neural correlate of context updating in working memory (Polich, 2007). According to this account, perceived stimuli are categorized as "target" or "non-targets": The neural representation of the stimulus environment remains unaffected by the presentation of nontargets, whereas the identification of targets results in the allocation of attentional resources and an updated neural representation of the stimulus environment (Polich, 2007). The $\mathrm{P} 3 \mathrm{~b}$ as an endogenous component depends on the individual's perception of stimuli as targets and their reaction onto them and is, therefore, dependent on the participant's willingness and ability to perform the requested task. Given this, it is not fully clear which cognitive processes in active oddball tasks are disrupted by ketamine. Is already the perception of stimuli impaired, becomes the differentiation of targets and non-targets more difficult, or are working memory functions compromised by the drug? All factors could in principle result in reduced P3b amplitudes.

Schwertner et al. (2018) recently reviewed previous studies investigating the impact of ketamine on the $\mathrm{P} 3 \mathrm{~b}$ in response to targets, the P3a in response to distractors, as well as on ERP components associated with sensory processing such as the auditory and visual P1 and N1 (Glossary). The authors reported that ketamine administration in healthy individuals was associated with decreases in certain ERP component amplitudes such as the P3b, whereas early ERP components such as the $\mathrm{P} 1$ and N1 were unaffected or even increased by ketamine. They suggest that "ketamine may alter the perceived salience of different categories of stimuli" and may lead to changes in cognitive resources dedicated in the interpretation of stimuli (Schwertner et al., 2018, p. 11). As an example, they line out that in oddball experiments the P3b amplitude to targets decreases and the P3a amplitude to distractors increases when the discriminability of standards and targets decreases and thus target identification becomes more difficult (Hagen et al., 2006). They then suggest that "If ketamine alters the perceived 


\section{Active oddball}

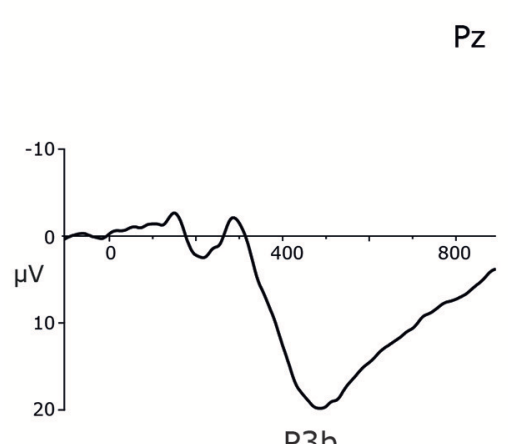

P3b

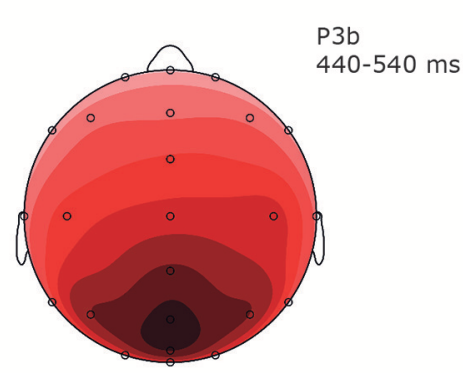

$0 \mu \mathrm{V}$

$20 \mu \mathrm{V}$

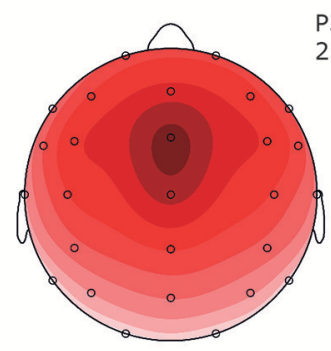

$0 \mu \mathrm{V}$

$3 a$

234-294 ms
(I) 2-stimulus oddball

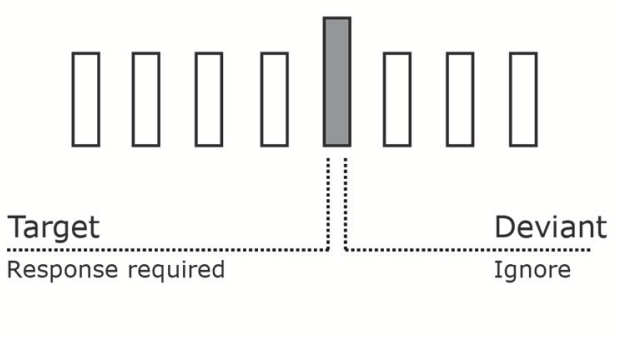

(II) n-back task

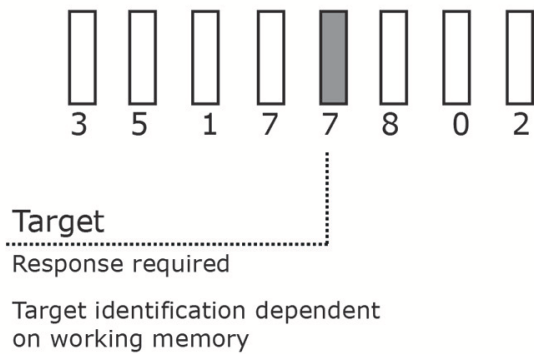

(III) 3-stimulus oddball

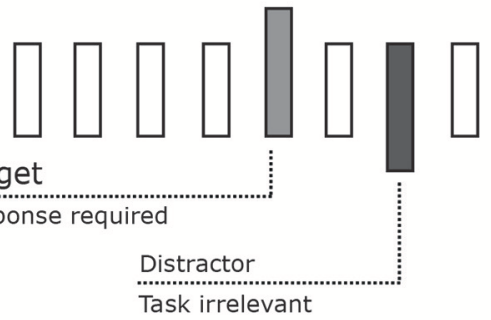

Passive oddball

$\mathrm{FCz}$
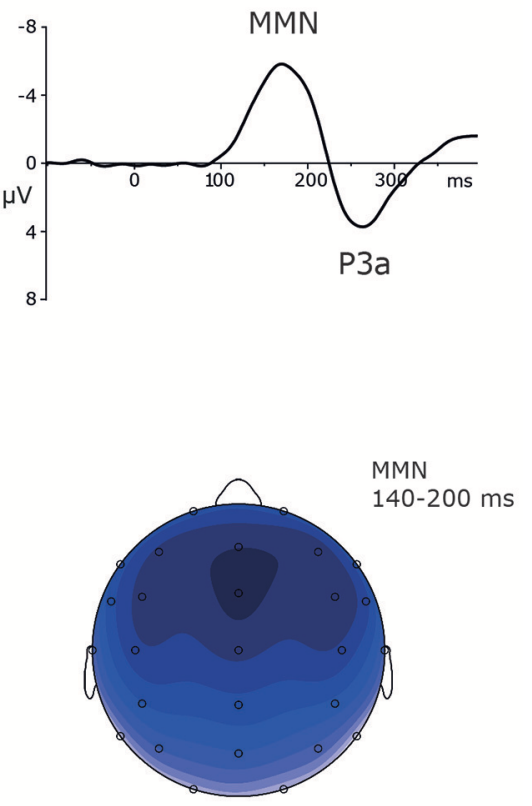

$-6 \mu \mathrm{V}$ $0 \mu \mathrm{V}$

FIGURE 1 | The figure shows three different types of oddball experiments. (I) The relatively common 2-stimulus oddball experiment contains two kinds of stimuli, one is frequently presented and the other less frequently, usually in $<20 \%$ of the trials. This kind of oddball can be used in active and passive conditions, primarily varying in their task instruction: In active oddball experiments, the rare stimulus is defined as target and requires an active response (e.g., a button press). Correctly identified targets elicit the P3b which maximal at centro-parietal electrodes and peaks between 250 and 500 ms (left top: the ERP response at electrode Pz, left middle: the scalp distribution of the P3b; data were recorded in a visual oddball experiment; Rosburg et al., unpublished data). In passive oddball experiments, participants ignore the stimuli. The rare stimulus is defined as deviant and elicits the MMN, which is fronto-central negativity between 100 and $250 \mathrm{~ms}$ (right top: the difference potential between the ERP to duration deviants and the ERP to standard tones; right middle: the scalp distribution of the MMN; data from Rosburg et al. (2018). (II) The n-back represents a variant of the 2-stimulus oddball task, which is with increasing $\mathrm{n}$ more WM dependent. In the depicted 1-back condition, an immediately repeated stimulus is defined as target. This variant has hardly been used in passive conditions and elicits only weak MMN responses (e.g. Rosburg, 2004). (III) For active conditions also quite common 3-stimulus oddball experiments contain rare distractor stimuli in addition to targets and standards. These distractors do not require a behavioral response. Due to their perceptual salience and rare presentation, distractors elicit a P3a, which is also observed in passive oddball experiments in response to deviants (left bottom: topography of the P3a in a passive oddball experiment, data from Rosburg et al. (2018).

relationship between the target and standard stimuli in the oddball task, it could potentially account for the P300 reductions and N100/P100 increases reported in most studies." (p. 11).

Following the argumentation of Schwertner et al. (2018), the decreased discriminability of standards and targets represents a direct drug effect of ketamine. This would suggest that ketamine directly impairs cognitive functions supporting the target detection due to its pharmacological properties. However, alternatively, individuals might experience greater difficulties in identifying targets due to the psychotomimetic effects of 
ketamine, e.g., participants might be distracted from the target identification due to drug-induced perceptual alterations (Krystal et al., 1994). In this case, one would argue that the ketamine effects reflected in the P3b amplitude reductions are more indirectly linked to the pharmacological properties of ketamine.

The current review aims at evaluating empirical evidence whether the ketamine-induced ERP alterations in active oddball experiments can be explained by an increased task difficulty, either directly related to ketamine's pharmacological properties or more indirectly to its psychotomimetic effects, or whether alternative mechanisms are more plausible. For this purpose, we initially review findings on the impact of increased task difficulty on the P3b and other ERP components. Then, we inspect ERP studies that have investigated the effects of ketamine in order to compare the observed ketamine effects with those induced by increased task difficulty. This comparison includes the ERP components P3a and P3b, P1, N1, and Processing Negativity $(\mathrm{PN})$, as well as the task accuracy.

\section{METHODS}

In the first result section, we present a selective review of previous studies showing how the ERP components P3a and P3b, P1, N1, and $\mathrm{PN}$ of healthy individuals are modulated by an increased task difficulty in active oddball tasks. Task difficulty in oddball experiments can be modulated by a range of factors (for review Kok, 2001), whereby here we focused on the effects of decreasing the discriminability of targets vs. non-targets, introducing a secondary task, increasing the task load of either the primary or secondary task, or by presenting distractor stimuli in the same or a different modality than targets. From our point of view, these experimental modulations mimic the hypothesized direct or indirect effects of ketamine best: Ketamine might decrease the ability to discriminate targets and standards, it might distract from the target detection task, or alternatively, it might diminish attentional and cognitive resources required for performing the target detection task. Moreover, the mentioned experimental variations of increasing the task difficulty correspond to tasks used in ketamine studies.

In the second result section, we review how the ERP components $\mathrm{P} 3 \mathrm{a}$ and $\mathrm{P} 3 \mathrm{~b}, \mathrm{P} 1, \mathrm{~N} 1$, and $\mathrm{PN}$ of healthy individuals are modulated by subanesthetic doses of ketamine. The review of ketamine effects is widely based on the same literature as the very recent review of Schwertner et al. (2018). However, studies were only included when the administered ketamine dose was large enough to evoke psychotomimetic effects in healthy participants. As suggested by the studies of Krystal et al. (1994) and Newcomer et al. (1999), it requires a bolus of more than $0.1 \mathrm{mg} / \mathrm{kg}$ or a bolus more than $0.0243 \mathrm{mg} / \mathrm{kg}$ followed by continuous injection of more than $0.012 \mathrm{mg} / \mathrm{kg}$ bodyweight per hour to observe such effects. We included ERP studies that were clearly above these thresholds (single bolus of $0.1-0.3 \mathrm{mg} / \mathrm{kg}$, eventually followed by a continuous injection of $0.135-0.9 \mathrm{mg} / \mathrm{kg}$ per hour, for a detailed listing of the used doses see Table 2 in Schwertner et al., 2018). Consequently, we excluded the studies of Murck et al. (2006) and Knott et al. (2011), administering doses clearly below these thresholds (Murck et al., 2006: no bolus and continuous injection of approximately $0.001 \mathrm{mg} / \mathrm{kg}$ per hour; Knott et al., 2011: single bolus of $0.04 \mathrm{mg} / \mathrm{kg}$ ). Knott et al. (2011) themselves qualified their study dose as "subperceptual." In variation from Schwertner et al. (2018), we did not consider the study of Umbricht et al. (2002) in this review, because the relevant data were the same as reported by Umbricht et al. (2000). From the study of Kort et al. (2017), we considered only data from the passive listening condition because the N1 suppression by speech production includes other processes than the sensory processing of the auditory stimuli. In contrast to Schwertner et al. (2018), we additionally included the prepulse inhibition study of Boeijinga et al. (2007), but only considered the pulse alone condition.

\section{RESULTS}

\section{Impact of Task Difficulty on ERPs}

An increased task difficulty is presumed to be reflected in poorer task accuracy and slower reaction times. Thus, experimental manipulations that seek to increase the task difficulty should always result in such behavioral changes. Indeed, most experimental manipulations successfully modulated the task difficulty as reflected in the two behavioral markers (Tables 1A-D, right columns).

\section{P1/N1/PN}

The impact of task difficulty on ERP components related to sensory processing, such as the auditory $\mathrm{N} 1$ or the visual P1, is not easily assessable. One factor contributing to this challenge is that both ERP components are modulated by physical characteristics of the auditory and visual stimuli (for review Näätänen and Picton, 1987; Tobimatsu and Celesia, 2006). In studies varying the perceptual task difficulty (or perceptual load), the physical characteristics of easy and difficult targets differed. A higher perceptual load is usually achieved by lower target-standard discriminability (Table 1A). In other words, difficult targets are more similar to standards than easy targets. Fitzgerald and Picton (1983) used a standard tone of $1,000 \mathrm{~Hz}$, a difficult target stimulus of $1,050 \mathrm{~Hz}$, and an easy target stimulus of 1,500 Hz. In this study, easy targets elicited a significantly larger N1 than difficult targets. For auditory stimulation, it is, however, a well-established finding that greater frequency separation results in less stimulus-specific adaptation (SSA) and, in consequence, larger N1 amplitudes (Butler, 1968; Ulanovsky et al., 2003; Briley and Krumbholz, 2013). Given these findings, the larger N1 amplitudes for easy targets as observed by Fitzgerald and Picton $(1983,1984)$ were likely caused by a lessened impact of SSA and unrelated to task difficulty.

Some of the studies varying the perceptual load included a passive oddball condition. This allowed investigating whether the attentional modulation differed between test conditions with varying perceptual task difficulty. Directed attention increases both the auditory N1 and visual P1 amplitudes (N1: Hillyard et al., 1973; Näätänen et al., 1981; Hackley et al., 1990; Woldorff and Hillyard, 1991; Alho et al., 1992; P1: Hopfinger and Mangun, 1998; Taylor, 2002). For auditory stimulation, this attention effect is usually quantified by calculating the difference potentials 
TABLE 1A | Decreased discriminability of standards and targets/task cues in active oddballs.

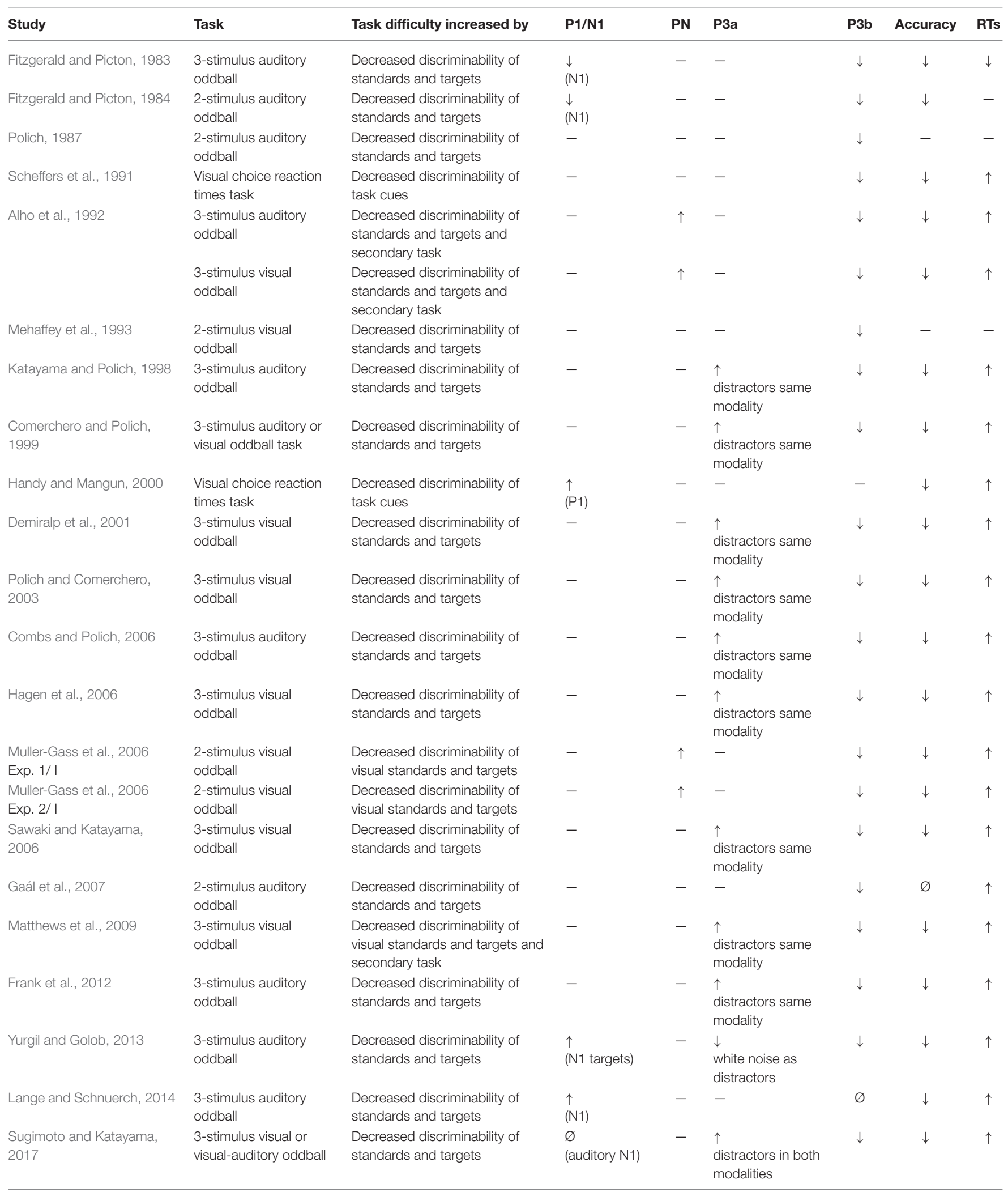

The table summarizes the previously reported effects of decreased discriminability of standards and targets (or other task cues) in active oddballs on the N1/P1, PN, P3a, and P3b amplitudes, as well as the resulting behavioral effects (accuracy and reactions times, RTS). Decreased discriminability should result in an increased task difficulty and, thus, should be reflected in decreased task accuracy $(\downarrow)$ and increased RTs $(\uparrow)$. For the ERP amplitudes, downward tilted arrows $(\downarrow)$ indicate decreased amplitudes, upward tilted arrows ( $\uparrow$ ) increased amplitudes, with decreased discriminability of standards and targets. Absent effects are indicated by " $\varnothing$ " and unreported effects by " -" 
TABLE 1B | Increased primary task difficulty in passive oddball experiments.

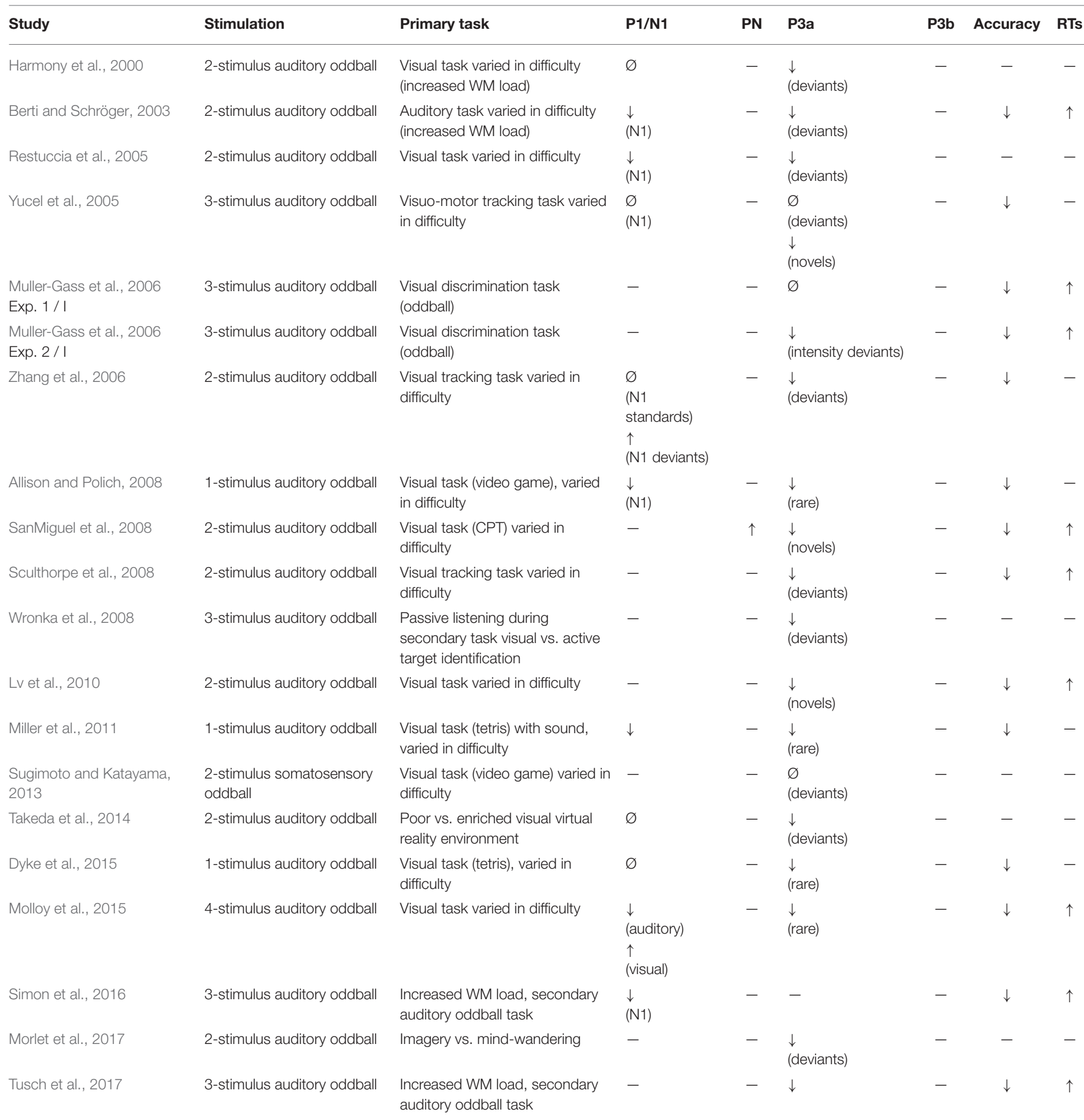

The table summarizes the previously reported effects of an increased primary task difficulty on the N1/P1, PN, and P3a amplitudes in passive oddball paradigms, as well as the resulting behavioral effects (accuracy and RTs) in the primary task. In passive oddball paradigms, the deviant is defined as task-irrelevant and does not require a behavioral response by the participant. Given this, there is no target-related P3b in the ERPS. For the purpose of the current review, the passive oddball paradigm is defined as secondary task ("stimulation"). For the meaning of the used symbols please see Table $\mathbf{1 A}$.

between the auditory evoked potentials (AEPs) to attended stimuli and non-attended stimuli. The increased negativity to attended auditory stimuli is labeled as PN (or Negativity difference, Nd) (Näätänen, 1982, 1990; Woldorff and Hillyard,
1991). Alho et al. (1992) and Muller-Gass et al. (2006) showed that increased perceptual task difficulty results in an increased PN (Table 1A). Other recent studies suggest that more difficult tasks require more attentional resources, leading to larger $\mathrm{P} 1$ and 
TABLE 1C | Dual task conditions.

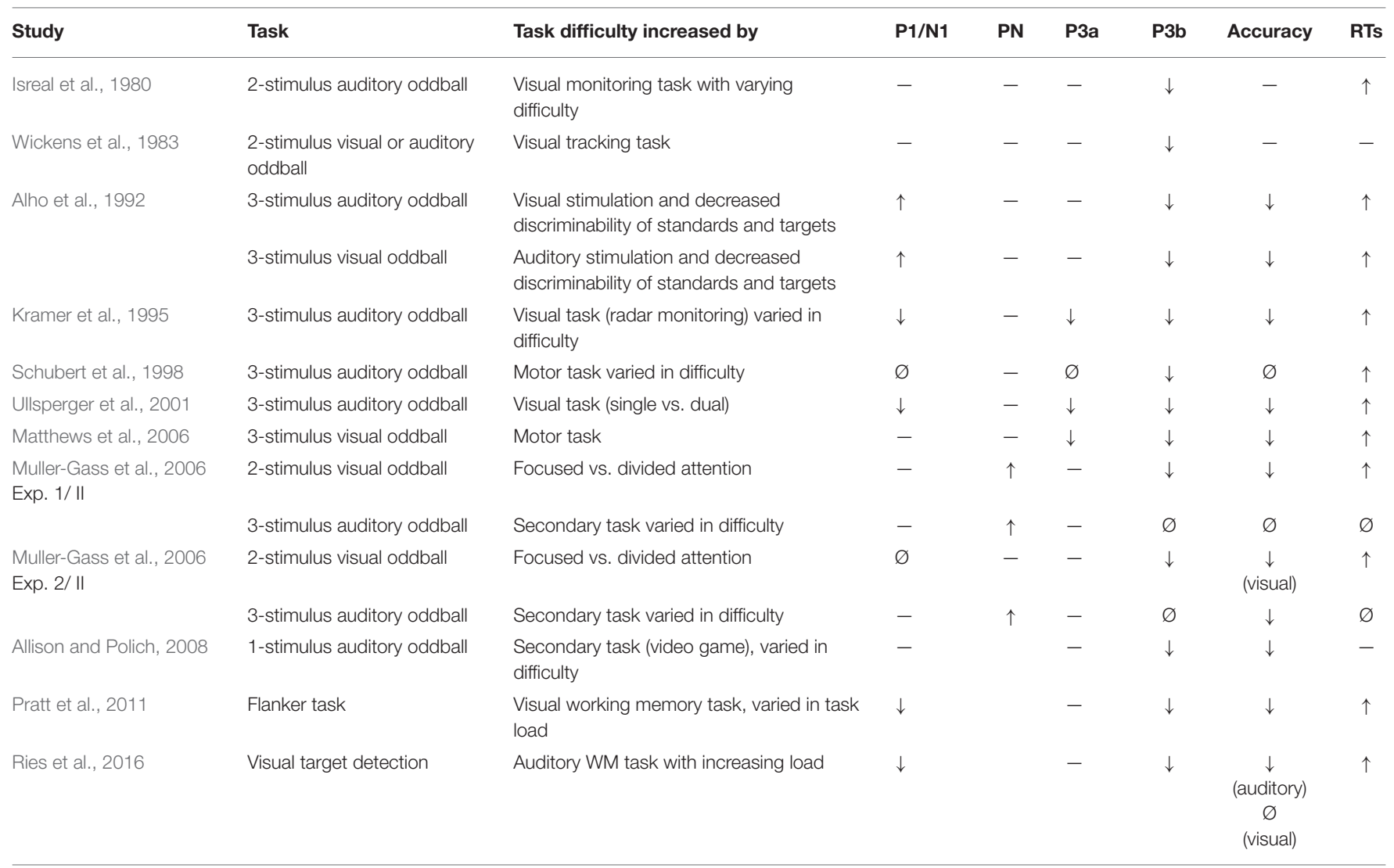

The table summarizes the previously reported effects of dual task conditions in active oddballs on the N1/P1, PN, P3a, and P3b amplitudes, as well as the resulting behavioral effects (accuracy and RTs). For the meaning of the used symbols please see Table $\mathbf{1 A}$.

N1 responses (Handy and Mangun, 2000; Lange and Schnuerch, 2014). In line with that, Schwent et al. (1976) showed that the attentional modulation of the auditory $\mathrm{N} 1$ is larger when sound events are harder to discriminate. Finally, increased levels of effort have been associated with increased N1 responses (Wilkinson and Morlock, 1967; Mulert et al., 2005, 2008). Thus, for active oddball paradigms, there is some evidence that increased perceptual load leads to increased P1 and N1 amplitudes.

Findings from passive oddball experiments with a primary task tend to show the opposite effect. In such experiments, participants are instructed to pay full attention to the primary task and to ignore the auditory stimulation. Under such conditions, more difficult primary tasks should be associated with decreased N1 amplitudes to the to-be-ignored auditory stimuli because with increasing task difficulty more attentional resources need to be allocated to the primary task. Indeed, reduced N1 amplitudes in passive oddball experiments have been reported for more demanding primary tasks (Berti and Schröger, 2003; Restuccia et al., 2005; Allison and Polich, 2008; Miller et al., 2011; Simon et al., 2016; Table 1B). With a more demanding primary visual task, Molloy et al. (2015) showed not only a decrease of the N1 amplitude to the to-be-ignored auditory stimuli, but interestingly also an increase of the visual P1. However, some studies observed no modulation of the auditory N1 with an increased primary task difficulty (Harmony et al., 2000; Yucel et al., 2005; Takeda et al., 2014; Dyke et al., 2015) and few studies revealed even increased N1 amplitudes (Zhang et al., 2006; SanMiguel et al., 2008).

In dual task conditions, findings are rather mixed, with some studies reporting decreased and others reporting increased P1/N1 amplitudes (Table 1C). Most studies did not instruct the participants to prioritize one task over the other (see Matthews et al., 2006 for an exception). Thus, increased task difficulty might lead to increased P1/N1 amplitudes in one task at the expense of decreased P1/N1 amplitudes in the second task, similarly as observed by Molloy et al. (2015).

\section{$\mathrm{P} 3 a / \mathrm{P} 3 \mathrm{~b}$}

The P3b is usually elicited in active oddball paradigms, using one frequent standard stimulus and one rare target stimulus, which requires a button press or needs to be counted (see Polich, 2007 for review). Already early studies suggested that increased task difficulty results in decreased P3b amplitudes (e.g., Isreal et al., 1980; Fitzgerald and Picton, 1983; Wickens et al., 1983) and this finding has repeatedly been replicated across different settings: Reduced P3b amplitudes with increased task difficulty have consistently been shown for studies 
TABLE 1D | Increased working memory (WM) load in active tasks.

\begin{tabular}{|c|c|c|c|c|c|c|c|c|}
\hline Study & Task & Task difficulty increased by & P1/N1 & PN & P3a & P3b & Accuracy & RTs \\
\hline Mecklinger et al., 1992 & Visual WM task & Increased WM load & - & - & - & $\downarrow$ & $\downarrow$ & $\uparrow$ \\
\hline Lorist et al., 1994 & Visual WM task & Increased WM load & - & - & $\begin{array}{c}\varnothing \\
\text { (irrelevant } \\
\text { visual cues) }\end{array}$ & $\downarrow$ & $\downarrow$ & $\uparrow$ \\
\hline McEvoy et al., 2001 & Visual WM task & Increased WM load & - & - & - & $\varnothing$ & $\downarrow$ & $\uparrow$ \\
\hline Watter et al., 2001 & Visual WM task & Increased WM load & - & - & - & $\downarrow$ & $\downarrow$ & $\uparrow$ \\
\hline SanMiguel et al., 2008 & Visual WM task & Increased WM load & - & $\uparrow$ & - & $\downarrow$ & $\downarrow$ & $\uparrow$ \\
\hline Chen and Mitra, 2009 & Visual WM task & Increased WM load & - & - & - & $\downarrow$ & $\downarrow$ & $\uparrow$ \\
\hline Ruhnau et al., 2010 & Visual WM task & $\begin{array}{l}\text { Increased WM load, 2-stimulus auditory } \\
\text { oddball (passive); auditory stimuli } \\
\text { preceded visual stimuli by } 600 \mathrm{~ms}\end{array}$ & - & - & $\begin{array}{c}\uparrow \\
\text { (auditory) }\end{array}$ & $\downarrow$ & $\downarrow$ & $\uparrow$ \\
\hline Daffner et al., 2011 & Visual WM task & Increased WM load & - & - & - & $\begin{array}{c}\downarrow / \uparrow \\
\text { depending on } \\
\text { performance }\end{array}$ & $\downarrow$ & $\uparrow$ \\
\hline Causse et al., 2016 & Visual tracking task & Increased WM load & - & - & - & $\downarrow$ & $\downarrow$ & - \\
\hline Simon et al., 2016 & Visual WM task & $\begin{array}{l}\text { Increased WM load, secondary auditory } \\
\text { oddball task }\end{array}$ & - & - & - & $\downarrow$ & $\downarrow$ & $\uparrow$ \\
\hline Tusch et al., 2016 & Visual WM task & Increased WM load & - & - & - & $\downarrow$ & $\downarrow$ & $\uparrow$ \\
\hline Jiang and Rau, 2017 & Visual WM task & Increased WM load & - & - & - & $\downarrow$ & $\downarrow$ & $\uparrow$ \\
\hline Scharinger et al., 2017 & Visual WM task & Increased WM load & - & - & - & $\downarrow$ & $\downarrow$ & $\uparrow$ \\
\hline Tusch et al., 2017 & Visual WM task & Increased WM load (multiple targets) & - & - & - & $\downarrow$ & $\downarrow$ & $\uparrow$ \\
\hline Zhang et al., 2017 & Visual WM task & Increased WM load & - & - & - & $\downarrow$ & $\downarrow$ & $\uparrow$ \\
\hline Gajewski and Falkenstein, 2018 & Visual WM task & Increased WM load & - & - & $\uparrow$ & $\downarrow$ & $\downarrow$ & $\uparrow$ \\
\hline
\end{tabular}

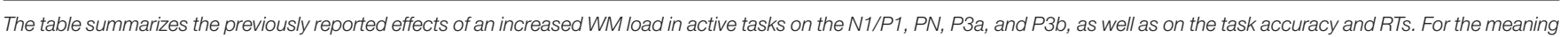
of the used symbols please see Table $\mathbf{1 A}$.

varying the perceptual load (Table 1A), dual task conditions (Table 1C), and studies varying the working memory (WM) load (Table 1D).

The $\mathrm{P} 3 \mathrm{a}$ is elicited by presenting rare events that considerably vary from the standards but do not require a response. These task-irrelevant events can distract individuals from the processing of task-relevant stimuli (Parmentier, 2014). When rare task-irrelevant events are presented within the same modality as the targets, the P3a amplitude (to these distractors) increases with increasing task difficulty (Katayama and Polich, 1998; Comerchero and Polich, 1999; Demiralp et al., 2001; Polich and Comerchero, 2003; Combs and Polich, 2006; Hagen et al., 2006; Matthews et al., 2009; Frank et al., 2012; Sugimoto and Katayama, 2017; Table 1A). This finding suggests that the processing of such distractors is more strongly engaged in harder target detection tasks. In contrast, when rare, task-irrelevant auditory stimuli had to be ignored and were presented during a primary visual task, the (early) P3a amplitude to these auditory stimuli decreased with increasing difficulty in the primary task or as compared to conditions without a visual task (Harmony et al., 2000; Restuccia et al., 2005; Yucel et al., 2005; MullerGass et al., 2006; Zhang et al., 2006; Allison and Polich, 2008; SanMiguel et al., 2008; Sculthorpe et al., 2008; Lv et al., 2010;
Miller et al., 2011; Dyke et al., 2015; Molloy et al., 2015; Morlet et al., 2017; Tusch et al., 2017, Table 1B). Even though the P3a in passive oddball tasks is considered to reflect an involuntary attention switch in response to sound deviance (Näätänen, 1990; Escera et al., 2000), the P3a is stronger when participants attend the auditory stimuli (Wronka et al., 2008). Thus, the decreased P3a amplitudes in passive oddball experiments with increasing difficulty in the primary task suggest that more attentional resources were dedicated to the primary task and less resources to listening to the auditory stimulation. In dual task conditions, demanding visual, and motor tasks might also lead to a reduction of the P3a to attended auditory stimuli (Kramer et al., 1995; Ullsperger et al., 2001; Matthews et al., 2006, Table 1C). Thus, with the greater need to focus attention on one modality, the processing of distractors in the second modality is suppressed.

At first glance, some findings appear to conflict with the described pattern. In a visual oddball task, Sugimoto and Katayama (2017) observed an increased P3a not only to visual distractors, what would be in line with other findings, but also to auditory distractors (Table 1A). What could explain an attentional spill-over from one modality to the other, which is constantly absent in passive oddball experiments? In their 
TABLE 2 | Effects of ketamine on ERP amplitudes and task performance.

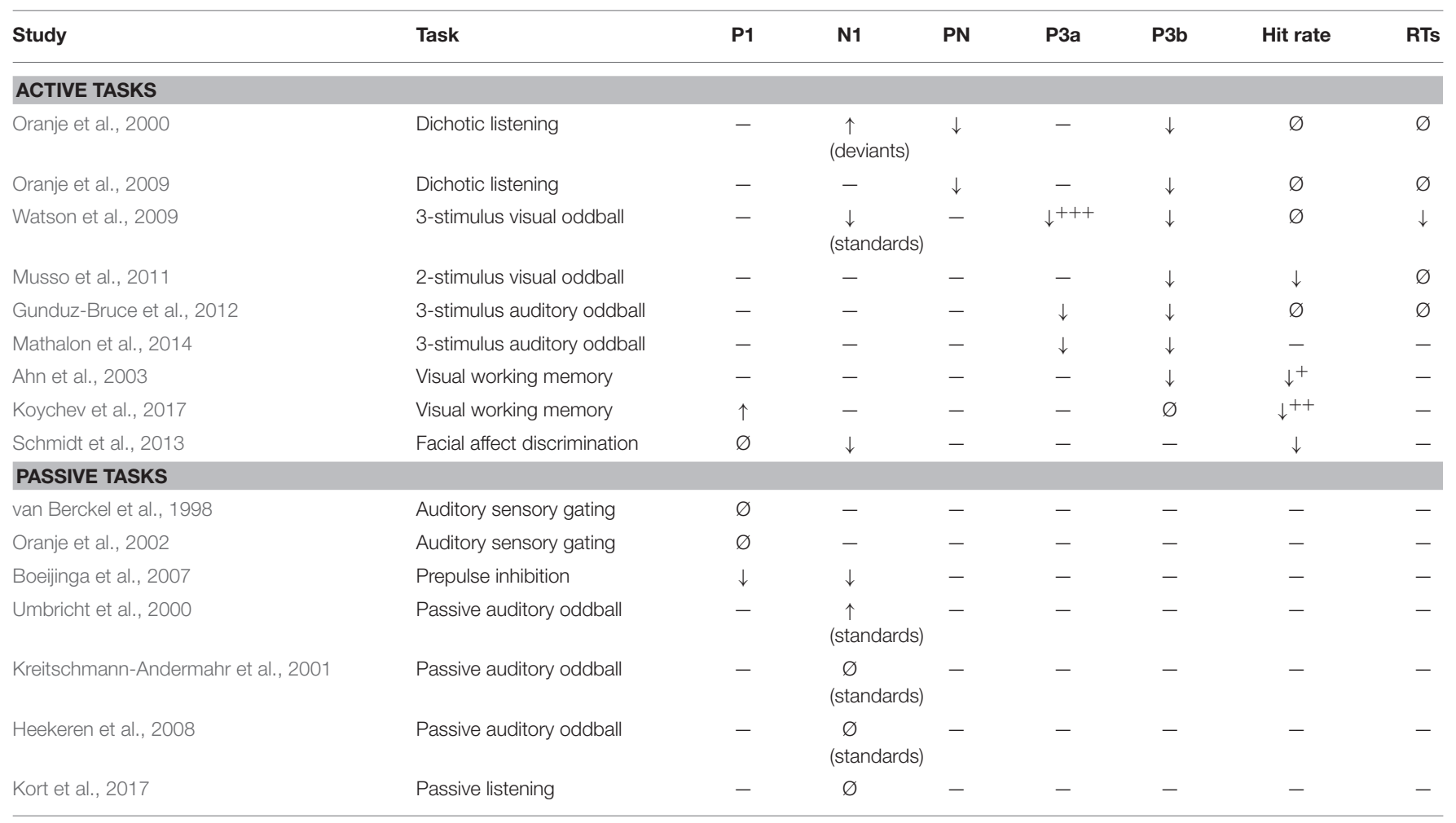

The table lists the reviewed ketamine studies and summarizes the effects of ketamine administration on ERP amplitudes, as well as on task accuracy and reaction times. The studies are ordered according to the used task and publication year. Reductions of the P3a and P3b amplitudes after ketamine represent a relatively consistent finding across studies. In all studies reporting P3a effects, the distractors were presented in the same modality as targets. ${ }^{+}$Marginally significant; ${ }^{++}$significant interaction between drug and working memory (WM) load; after ketamine task accuracy decreased more with increasing task load than after placebo; +++ only at Pz. For the meaning of the used symbols please see Table $\mathbf{1 A}$.

experimental set-up, Sugimoto and Katayama (2017) replaced the visual distractor by an auditory distractor. Thus, the distracting event was not only characterized by a rare sound, but also by an absent visual stimulation. Therefore, the "auditory" distractor in this study actually represented an audio-visual distractor. Similarly, Ruhnau et al. (2010) observed an increased P3a to auditory cues in a visual WM task with increasing task load (Table 1D), again indicating some attentional spill-over from one modality to the other. In their study, the auditory cues always preceded the visual stimuli by $600 \mathrm{~ms}$. In other words, the auditory cues informed about the timing of the to-be-attended visual stimuli and were therefore likely not ignored.

\section{Impact of Ketamine on ERPs $\mathrm{P} 1 / \mathrm{N} 1 / \mathrm{PN}$}

In their recent review of ketamine effects on ERPs, Schwertner et al. (2018) summarized that the P1 and N1 amplitudes remain stable after ketamine administration or are even increased. However, it is not clear why Schwertner et al. (2018) neglected findings demonstrating decreased $\mathrm{P} 1$ and $\mathrm{N} 1$ amplitudes after ketamine, as reported by Boeijinga et al. (2007) for the neuromagnetic P1 and N1 to auditory stimuli (pulse only), Watson et al. (2009) for visual N1 to standards, or Schmidt et al. (2013) for the N170 in response to emotional face stimuli. The findings on alterations of the $\mathrm{P} 1 / \mathrm{N} 1$ after ketamine are indeed rather mixed, with most studies reporting no drug effect on the P1/N1 and with the same number of studies reporting either decreased or increased P1/N1 amplitudes after ketamine (Table 2).

Watson et al. (2009) analyzed their data also in respect whether sensory deficits induced by ketamine (as reflected in the diminished N1 amplitude to standards) could contribute to the reduced $\mathrm{P} 3 \mathrm{a} / \mathrm{P} 3 \mathrm{~b}$ after ketamine. However, they did not find any associations between these effects. Moreover, Schmidt et al. (2013) did not reveal any association between the drug-induced worsened performance in emotional face recognition and the likewise reduced N170 response to these stimuli. Both findings argue against a link between the experienced task difficulty and ketamine-related $\mathrm{P} 1 / \mathrm{N} 1$ reductions.

Two studies investigated the effects of ketamine on the PN and revealed decreased PN amplitudes after ketamine (Oranje et al., 2000, 2009). As outlined above, increased task difficulty to attended stimuli is associated with increased PN amplitudes (Schwent et al., 1976; Alho et al., 1992; Muller-Gass et al., 2006), reflecting the increased allocation of attentional resources under such conditions. Diminished PN amplitudes after ketamine would thus not conform to the idea that participants experienced the task as more difficult after ketamine. Conversely, increased task difficulty in a primary task is associated with decreased N1 amplitudes to ignored stimuli (Alho et al., 1992; Restuccia et al., 2005; Allison and Polich, 2008; Miller et al., 2011; Molloy et al., 
2015; Simon et al., 2016), whereas the N1 in passive listening tasks was found to be unaffected (Kreitschmann-Andermahr et al., 2001; Heekeren et al., 2008; Kort et al., 2017) or increased (Umbricht et al., 2000) after ketamine.

Nevertheless, the rather mixed findings regarding the ketamine effects on the auditory and visual $\mathrm{P} 1 / \mathrm{N} 1$ suggest that this field requires further research in order to clarify whether ketamine has or has not systematic effects on early sensory processing. On the basis of the available information, findings in one or the other direction can hardly be invalidated, although maybe with one exception: Most studies reporting significant effects on the P1/N1 used a cross-over double-blind design. In contrast, Koychev et al. (2017) investigated the effects of workload on working memory and ERPs after either ketamine or placebo administration in two distinct samples and did not include a pre-infusion baseline recording either. A comparison between the P1 data of Koychev et al. (2017) and a second study of this group using the same experimental design suggests that the P1 in the ketamine group was in the range of other healthy controls, whereas the P1 in the placebo group was comparably small (Koychev et al., 2010). With other words, the reported P1 effect of Koychev et al. (2017) was likely not due to ketamine, but to sample characteristics.

Aside from the mixed findings in human studies, more studies on the effects of ketamine on sensory ERPs are also required because of discrepancies between human and animal studies. Two studies on monkeys provide a relatively consistent pattern of results and suggest that the effects of NMDA receptor antagonists on the P1/N1 to auditory stimuli crucially depend on the interstimulus interval (ISI), with reduced P1/N1 amplitudes after ketamine administration becoming more apparent at long ISIs (Javitt et al., 2000; Holliday et al., 2017). These animal data might provide an explanation why some human studies did not observe a modulation of the $\mathrm{P} 1 / \mathrm{N} 1$ after ketamine, as these studies used short ISIs (Kreitschmann-Andermahr et al., 2001; Heekeren et al., 2008; Kort et al., 2017). However, both the absence of decreased auditory P1 amplitudes after ketamine at long ISIs (van Berckel et al., 1998; Oranje et al., 2002) as well as the observation of increased auditory N1 amplitudes after ketamine (both at short and long ISIs) (Oranje et al., 2000; Umbricht et al., 2000) conflict with the animal data and cannot be attributed to methodological aspects.

\section{P3a/ P3b/ Task Accuracy}

Effects of ketamine on the P3b were investigated in 8 studies, with 4 studies using an oddball paradigm (Watson et al., 2009; Musso et al., 2011; Gunduz-Bruce et al., 2012; Mathalon et al., 2014), as well as 2 studies each using a working memory paradigm (Ahn et al., 2003; Koychev et al., 2017) and dichotic listening task (Oranje et al., 2000, 2009). Seven of these studies revealed decreased $\mathrm{P} 3 \mathrm{~b}$ amplitudes after ketamine (Table 2). The decreased P3b amplitudes after ketamine exposure appears to indicate that participants experienced the task as more difficult, given the plethora of studies showing that increased task difficulty is associated with decreased P3b amplitudes (e.g., Isreal et al., 1980; Fitzgerald and Picton, 1983, 1984; Wickens et al., 1983; Polich, 1987; Alho et al., 1992; Muller-Gass et al., 2006; Allison and Polich, 2008; Ruhnau et al., 2010; Pratt et al., 2011; Ries et al., 2016; Scharinger et al., 2017).

The impact of ketamine on task performance was quantified in 7 of these studies. 3 studies (including both WM task studies) reported diminished task accuracy after ketamine (Ahn et al., 2003; Musso et al., 2011; Koychev et al., 2017), whereas 4 studies observed no such effect (Oranje et al., 2000, 2009; Watson et al., 2009; Gunduz-Bruce et al., 2012). Ketamine effects on attention have been reported to depend on the WM load: in behavioral experiments, ketamine induced deficits were absent when the WM load was low (Harborne et al., 1996; Adler et al., 1998; Newcomer et al., 1999; Lofwall et al., 2006; Ebert et al., 2012), but present with increasing load (Adler et al., 1998; Lofwall et al., 2006; Koychev et al., 2017). A diminished task accuracy for WM tasks (Ahn et al., 2003), but not for other attention tasks (Oranje et al., 2000, 2009; Watson et al., 2009; Gunduz-Bruce et al., 2012) would fit to this pattern. The only exception from this pattern is the study of Musso et al. (2011), which showed a decrease in the hit rate in a quite simple target detection task after ketamine. This finding is somewhat surprising given that high levels of blood alcohol do not result in increased error rates in this kind of task (Colrain et al., 1993). Bearing in mind that the study of Musso et al. (2011) was conducted in an MRI scanner environment, one tentative explanation for the behavioral disruption in this easy task might be that the scanner noise functioned as potent distractor and not ketamine, but the combination of ketamine and distractor led to the behavioral impairment. In any case, in four of five studies that used a working memory-independent attention task the P3 amplitude reduction after ketamine was not accompanied by a lower task performance (Oranje et al., 2000, 2009; Watson et al., 2009; Gunduz-Bruce et al., 2012). Given this, it appears unlikely that P3b amplitude reduction after ketamine can be considered as consequence of an increased task difficulty.

Ketamine effects on the P3a were investigated in three active oddball studies (Watson et al., 2009; Gunduz-Bruce et al., 2012; Mathalon et al., 2014). In all three studies, the novel stimuli as distractors were presented in the same modality as the targets. All three reported decreased $\mathrm{P} 3 \mathrm{a}$ amplitudes at electrodes $\mathrm{Cz}$ and $\mathrm{Pz}$ after ketamine administration. In addition, Watson et al. (2009) further reported a $\mathrm{P} 3 \mathrm{a}$ amplitude increase at electrode $\mathrm{Fz}$ after ketamine relative to placebo administration, which was, however, not replicated by Gunduz-Bruce et al. (2012) and Mathalon et al. (2014). The finding of a P3a amplitude increase at Fz might have been due to pre-infusion differences between conditions, with significantly larger pre-infusion P3a amplitudes at this electrode for the placebo than ketamine session (Watson et al., 2009). Across drug-sessions, the post-infusion P3a amplitudes at Fz were smaller in the ketamine than placebo condition (Table 2 in Watson et al., 2009). In other words, the evidence for increased P3a amplitudes after ketamine in this study is at best very modest. Increased task difficulty usually results in increased P3a when distractors and targets are presented in the same modality (Table 1A). The observed decrease in P3a amplitudes after ketamine across the three studies clearly conflicts with the assumption that participants experienced the task as more difficult after ketamine. 


\section{DISCUSSION}

The current review evaluates empirical evidence whether the ketamine-induced ERP alterations in active oddball experiments can be explained by a drug-related decreased discriminability of targets and standards, resulting in an increased task difficulty, as suggested by Schwertner et al. (2018). The major commonalities and discrepancies of ketamine and task difficulty effects on ERP components and the task accuracy are summarized in Table 3. Both ketamine and increased task difficulty are associated with decreased P3b amplitudes. However, the P3b amplitude decrease after ketamine cannot be referred to poorer task performance as the P3b amplitude reductions after ketamine were often not accompanied by a poorer task accuracy in attention tasks (Oranje et al., 2000, 2009; Watson et al., 2009; Gunduz-Bruce et al., 2012; but Musso et al., 2011). The lack of behavioral impairments in oddball and dichotic listening tasks after ketamine are in line with the assumption that the attentional impairments induced by ketamine are restricted to WM-dependent tasks, as for instance shown in the behavioral studies of Adler et al. (1998) and Lofwall et al. (2006). More importantly, not only the P3b but also the P3a amplitudes in response to distractors presented in the same modality were reduced after ketamine (Watson et al., 2009; Gunduz-Bruce et al., 2012; Mathalon et al., 2014), whereas increased task difficulty resulted exclusively in increased P3a amplitudes for such distractors (Comerchero and Polich, 1999; Demiralp et al., 2001; Polich and Comerchero, 2003; Hagen et al., 2006; Sugimoto and Katayama, 2017). Moreover, increased task difficulty leads to an increased PN (Schwent et al., 1976; Alho et al., 1992; Muller-Gass et al., 2006), whereas the PN was found to be reduced after ketamine (Oranje et al., 2000, 2009). In passive oddball experiments, increased task load in the primary task has been associated with decreased N1 amplitudes, which contrasts to ketamine studies reporting either no effects (KreitschmannAndermahr et al., 2001; Heekeren et al., 2008) or an increased N1 amplitude (Umbricht et al., 2000).

Overall, there is only weak empirical evidence that ketamine leads to decreased discriminability of standard and target stimuli, as suggested by Schwertner et al. (2018). The pattern of findings also argues against the assumption that the $\mathrm{P} 3 \mathrm{~b}$ amplitude reduction after ketamine could be an indirect consequence of the psychotomimetic effects of ketamine, with participants experiencing greater difficulties in performing the task after drug administration. What mechanism could provide an alternative explanation for the P3b reductions after ketamine? The most common model of the functional significance of the P3b is the context updating theory, which proposes that an incoming stimulus is compared in WM with neural representation of the previous stimulation and, in case of deviance, leads to an update of this representation (Polich, 2007). This conceptualization suggests that the P3b reflects WM-dependent functions. Thus, even though targets and non-targets are correctly classified after ketamine, the behavioral consequence in form of an update of the neural context representation might be impaired and this appears to be equally the case for targets and distractors, resulting in the reduced P3a and P3b amplitudes. Given this, the reduced P3a and P3b amplitudes might be considered as
TABLE 3 | Comparison of task difficulty and ketamine effects.

\begin{tabular}{lccc}
\hline & $\begin{array}{c}\text { Increased task } \\
\text { difficulty }\end{array}$ & $\begin{array}{c}\text { Ketamine } \\
\text { administration }\end{array}$ & Comparison \\
\hline $\begin{array}{l}\text { Task accuracy in WM } \\
\text { independent attention task }\end{array}$ & $\downarrow$ & $\varnothing$ & $\neq$ \\
$\begin{array}{l}\text { N1 amplitude (ignored } \\
\text { stimuli) }\end{array}$ & $\downarrow$ & $\varnothing / \uparrow$ & $\neq$ \\
$\begin{array}{l}\text { PN amplitude (attended } \\
\text { stimuli) }\end{array}$ & $\uparrow$ & $\downarrow$ & $\neq$ \\
P3b amplitude to targets & $\downarrow$ & $\downarrow$ & $=$ \\
$\begin{array}{l}\text { P3a amplitude to distractors } \\
\text { in the same modality }\end{array}$ & $\uparrow$ & $\downarrow$ & $\neq$ \\
\hline
\end{tabular}

The table contrasts the major findings on the impact of increased task difficulty and of ketamine administration for the task accuracy in working memory independent attention task, the $\mathrm{N} 1$ amplitude in passive oddball paradigms, the PN as effect of attention, on the P3b to targets, and the P3a to distractors presented in the same modality as targets. The left column ("Increased task difficulty") represents a summary of findings described in Tables $\mathbf{1 A - D}$, the middle column ("Ketamine administration") represents a summary of Table 2, and right column summarizes the contrast between the effects of ketamine administration and increased task difficulty, with " $=$ " indicating similar effects, and " $\neq$ " indicating dissimilar or contrary effects.

another evidence for an impairment of WM functions after ketamine.

This failure to update neural context representations might primarily be related to encoding deficits: Already in early studies, a disruption in episodic memory after ketamine has been reported (e.g., Krystal et al., 1994; Newcomer et al., 1999). Specifying the nature of this disruption, Hetem et al. (2000) and Lofwall et al. (2006) showed that in particular the encoding of new episodic information is impaired after ketamine, whereas retention and retrieval of information encoded directly before the ketamine administration remain unaffected. In an fMRI study on the effects of ketamine on spatial working memory, Driesen et al. (2013) observed a reduction of brain activation during encoding and early maintenance after ketamine, providing further support for an impairment of encoding processes by ketamine. The reduced MMN after ketamine might as well be interpreted as a deficit in forming memory traces (Umbricht et al., 2000; Schmidt et al., 2012; Rosburg and Kreitschmann-Andermahr, 2016). Of note, theoretical conceptualizations of the MMN highlight the role of the repetitive presentation of standards, with more presentations of standards leading to a more pronounced neural model and a larger MMN (Javitt et al., 1998), whereas the P3 context updating account highlights the update of the model by the target/distractor (Polich, 2007). The functional association between the MMN and P3a are still a matter of debate (e.g., Horváth et al., 2008; Rosburg et al., 2018). Further research is needed to elucidate whether the reduced P3a, P3b, and MMN after ketamine refer to disruptions of the same or different encoding processes.

In general, behavioral, neurophysiological, and neuroimaging studies on ketamine effects in healthy individuals have improved our understanding of a possible contribution of a deficient glutamatergic neurotransmission to symptoms and cognitive deficits in schizophrenia. On the basis of the NMDA receptor hypofunction hypothesis (Javitt, 2010; Kantrowitz and Javitt, 
2012), new treatment strategies for schizophrenic symptoms have been stimulated, including the development of novel antipsychotic drugs. These new treatment strategies seek to improve the glutamatergic neurotransmission by ligands which bind to glycine sites of the NMDA receptor, such as d-serine and glycine, and by glycine transport inhibitors, as add-on medication to conventional anti-psychotics (Javitt, 2010; Balu and Coyle, 2015). In their meta-analysis, Cho et al. (2016) showed for example that $\mathrm{d}$-serine levels were generally decreased in schizophrenia and that d-serine as add-on medication improved both positive and negative symptoms. The MMN, but to the best of our knowledge not the P3a and P3b, has been used as neurophysiological marker in some of these studies. In a recent study, Greenwood et al. (2018) showed that a 6week treatment with glycine improved in particular negative symptoms. However, effects of glycine treatment on the MMN to duration deviants were not observed after 6 weeks of treatment, but only directly after the first glycine administration. Kantrowitz et al. (2018) observed a clinical improvement and an increase of the MMN amplitude to frequency deviants after a 6-week treatment with $\mathrm{d}$-serine, with both effects being correlated. In contrast, the authors reported that treatment with the glycine transport inhibitor bitopertin had neither clinical effects nor effects on the MMN. Nevertheless, a larger randomized, doubleblind phase II proof-of-concept study (without using ERPs) revealed an improvement of negative symptoms after 8 weeks of treatment with bitopertin (Umbricht et al., 2014). The sample sizes in the ERP studies of Greenwood et al. (2018) and Kantrowitz et al. (2018) were relatively small. Further research on larger patient samples is required to reveal whether clinical improvements after such novel treatments co-vary with

\section{REFERENCES}

Adler, C. M., Goldberg, T. E., Malhotra A, K., Pickar, D., and Breier, A. (1998). Effects of ketamine on thought disorder, working memory, and semantic memory in healthy volunteers. Biol. Psychiatry 43, 811-816. doi: 10.1016/S0006-3223(97)00556-8

Ahn, K. H., Youn, T., Cho, S. S., Ha, T. H., Ha, K. S., Kim, M. S., et al. (2003). N-Methyl-D-aspartate receptor in working memory impairments in schizophrenia: Event-related potential study of late stage of working memory process. Prog Neuro-Psychopharmacol. Biol. Psychiatry 27, 993-999. doi: 10.1016/S0278-5846(03)00159-3

Alho, K., Woods, D. L., Algazi, A., and Näätänen, R. (1992). Intermodal selective attention. II.Effects of attentional load on processing of auditory and visual stimuli in central space. Electroencephalogr. Clin. Neurophysiol. 82, 356-368.

Allison, B. Z., and Polich, J. (2008). Workload assessment of computer gaming using a single-stimulus event-related potential paradigm. Biol. Psychol. 77, 277-283. doi: 10.1016/j.biopsycho.2007.10.014

Balu, D. T., and Coyle, J. T. (2015). The NMDA receptor 'glycine modulatory site' in schizophrenia: d-serine, glycine, and beyond. Curr. Opin. Pharmacol. 20, 109-115. doi: 10.1016/j.coph.2014.12.004

Bentin, S., Allison, T., Puce, A., Perez, E., and McCarthy, G. (1996). Electrophysiological studies of face perception in humans. J. Cogn. Neurosci. 8, 551-565. doi: 10.1162/jocn.1996.8.6.551

Berti, S., and Schröger, E. (2003). Working memory controls involuntary attention switching: evidence from an auditory distraction paradigm. Eur. J. Neurosci. 17, 1119-1122. doi: 10.1046/j.1460-9568.2003.02527.x alterations of ERP markers, like the MMN, P3a, and P3b amplitude. Moreover, these ERP markers might also be used to identify patients who might benefit from such treatment (Swerdlow et al., 2018).

\section{CONCLUSION}

The conjoint reduction of the target-related $\mathrm{P} 3 \mathrm{~b}$ and the distractor-related P3a after ketamine administration conflicts with the assumption that ketamine alters the perceived salience of different categories of stimuli, as proposed by Schwertner et al. (2018). Rather, the combined reduction of the P3a and P3b suggests impaired WM updating, possibly related to general deficits in encoding of information after ketamine. Also the observation of a reduced MMN after ketamine fits well into this account (Rosburg and Kreitschmann-Andermahr, 2016). Both the $\mathrm{P} 3 \mathrm{a} / \mathrm{P} 3 \mathrm{~b}$ and the MMN might be used as neurophysiological marker for assessing the effects of drug treatments that seek to improve the glutamatergic neurotransmission.

\section{AUTHOR CONTRIBUTIONS}

TR searched and reviewed the literature. TR drafted the initial version of the manuscript. TR and AS were involved in the finalization of the submitted manuscript and discussed the significance of the findings.

\section{ACKNOWLEDGMENTS}

The authors thank Ms Tita Gonzalez Avilés for her assistance in language editing.

Boeijinga, P. H., Soufflet, L., Santoro, F., and Luthringer, R. (2007). Ketamine effects on CNS responses assessed with MEG/EEG in a passive auditory sensory-gating paradigm: an attempt for modelling some symptoms of psychosis in man. J. Psychopharmacol. 21, 321-337. doi: $10.1177 / 0269881107077768$

Bramon, E., Rabe-Hesketh, S., Sham, P., Murray, R. M., and Frangou, S. (2004). Meta-analysis of the P300 and P50 waveforms in schizophrenia. Schizophr. Res. 1, 315-329. doi: 10.1016/j.schres.2004.01.004

Breier, A., Malhotra, A. K., Pinals, D. A., Weisenfeld, N. I., and Pickar, D. (1997). Association of ketamine-induced psychosis with focal activation of the prefrontal cortex in healthy volunteers. Am. J. Psychiatry 154, 805-811. doi: 10.1176/ajp.154.6.805

Briley, P. M., and Krumbholz, K. (2013). The specificity of stimulus-specific adaptation in human auditory cortex increases with repeated exposure to the adapting stimulus. J. Neurophysiol. 110, 2679-2688. doi: 10.1152/jn.01015.2012

Butler, R. A. (1968). Effect of changes in stimulus frequency and intensity on habituation of the human vertex potential. J. Acoust Soc. Am. 44, 945-950. doi: $10.1121 / 1.1911233$

Causse, M., Peysakhovich, V., and Fabre, E. F. (2016). High working memory load impairs language processing during a simulated piloting task: an ERP., and pupillometry study. Front Hum Neurosci. 10:1-14. doi: 10.3389/fnhum.2016.00240

Chen, Y.-N., and Mitra, S. (2009). The spatial-verbal difference in the n-back task: an ERP study. Acta Neurol Taiwan. 18, 170-179.

Cho, S. E., Na, K. S., Cho, S. J., and Kang, S. G. (2016). Low D-serine levels in schizophrenia: a systematic review and meta-analysis. Neurosci. Lett. 634, 42-51. doi: 10.1016/j.neulet.2016.10.006 
Colrain, I. M., Taylor, J., McLean, S., Buttery, R., Wise, G., and Montgomery, I. (1993). Dose dependent effects of alcohol on visual evoked potentials. Psychopharmacology 112, 383-388. doi: 10.1007/BF02244937

Combs, L. A., and Polich, J. (2006). P3a from auditory white noise stimuli. Clin. Neurophysiol. 117, 1106-1112. doi: 10.1016/j.clinph.2006.01.023

Comerchero, M. D., and Polich, J. (1999). P3a and P3b from typical visual and auditory stimuli. Clin. Neurphysiol. 110, 24-30. doi: 10.1016/S0168-5597(98)00033-1

Daffner, K. R., Chong, H., Sun, X., Tarbi, E. C., Riis, J. L., McGinnis, S. M., et al. (2011). Mechanisms underlying age-and performancerelated differences in working memory. J. Cogn. Neurosci. 23, 1298-314. doi: 10.1162/jocn.2010.21540

Demiralp, T., Ademoglu, A., Comerchero, M., and Polich, J. (2001). Wavelet analysis of $\mathrm{P} 3 \mathrm{a}$ and P3b. Brain Topogr. 13, 251-267. doi: 10.1023/A:1011102628306

Driesen, N. R., McCarthy, G., Bhagwagar, Z., Bloch, M. H., Calhoun, V. D., D'Souza, D. C., et al. (2013). The impact of NMDA receptor blockade on human working memory-related prefrontal function and connectivity. Neuropsychopharmacology 38, 2613-2622. doi: 10.1038/npp.2013.170

Duncan, C. C., Barry, R. J., Connolly, J. F., Fischer, C., Michie, P. T., Näätänen, R., et al. (2009). Event-related potentials in clinical research: guidelines for eliciting, recording, and quantifying mismatch negativity, P300, and N400. Clin. Neurophysiol. 120, 1883-1908. doi: 10.1016/j.clinph.2009.07.045

Dyke, F. B., Leiker, A. M., Grand, K. F., Godwin, M. M., Thompson, A. G., Rietschel, J. C., et al. (2015). The efficacy of auditory probes in indexing cognitive workload is dependent on stimulus complexity. Int. J. Psychophysiol. 95, 56-62. doi: 10.1016/j.ijpsycho.2014.12.008

Earls, H. A., Curran, T., and Mittal, V. (2016). A meta-analytic review of auditory event-related potential components as endophenotypes for schizophrenia: perspectives from first-degree relatives. Schizophr. Bull. 42, 1504-1516. doi: $10.1093 /$ schbul/sbw047

Ebert, A., Haussleiter, I. S., Juckel, G., Brüne, M., and Roser, P. (2012). Impaired facial emotion recognition in a ketamine model of psychosis. Psychiatry Res. 200, 724-727. doi: 10.1016/j.psychres.2012.06.034

Erickson, M. A., Ruffle, A., and Gold, J. M. (2016). A meta-analysis of mismatch negativity in schizophrenia: from clinical risk to disease specificity and progression. Biol. Psychiatry 79, 980-987. doi: 10.1016/j.biopsych.2015.08.025

Escera, C., Alho, K., Schröger, E., and Winkler, I. (2000). Involuntary attention and distractibility as evaluated with event-related brain potentials. Audiol Neurootol. 5, 151-166. doi: 10.1159/000013877

Fitzgerald, P. G., and Picton, T. W. (1983). Event-related potentials recorded during the discrimination of improbable stimuli. Biol. Psychol. 17, 241-276. doi: 10.1016/0301-0511(83)90003-0

Fitzgerald, P. G., and Picton, T. W. (1984). The effects of probability and discriminability on the evoked potentials to unpredictable stimuli. Ann. N. Y. Acad. Sci. 425, 199-203. doi: 10.1111/j.1749-6632.1984.tb23533.x

Frank, D. W., Yee, R. B., and Polich, J. (2012). P3a from white noise. Int. J. Psychophysiol. 85, 236-241. doi: 10.1016/j.ijpsycho.2012.04.005

Gaál, Z. A., Csuhaj, R., and Molnár, M. (2007). Age-dependent changes of auditory evoked potentials-Effect of task difficulty. Biol. Psychol. 76, 196-208. doi: 10.1016/j.biopsycho.2007.07.009

Gajewski, P. D., and Falkenstein, M. (2018). ERP and behavioral effects of physical and cognitive training on working memory in aging: a randomized controlled study. Neural. Plast 2018, 1-12. doi: 10.1155/2018/3454835

Greenwood, L. M., Leung, S., Michie, P. T., Green, A., Nathan, P. J., Fitzgerald, P., et al. (2018). The effects of glycine on auditory mismatch negativity in schizophrenia. Schizophr. Res. 191, 61-69. doi: 10.1016/j.schres.2017.05.031

Gunduz-Bruce, H., Reinhart, R. M. G., Roach, B. J., Gueorguieva, R., Oliver, S., D'Souza, D. C., et al. (2012). Glutamatergic modulation of auditory information processing in the human brain. Biol. Psychiatry 71, 969-977. doi: 10.1016/j.biopsych.2011.09.031

Hackley, S. A., Woldorff, M., and Hillyard, S. A. (1990). Crossmodal selective attention effects on retinal, myogenic, brainstem, and cerebral evoked potentials. Psychophysiology 27, 195-208. doi: 10.1111/j.1469-8986.1990.tb00370.x

Hagen, G. F., Gatherwright, J. R., Lopez, B. A., and Polich, J. (2006). P3a from visual stimuli: task difficulty effects. Int. J. Psychophysiol. 59, 8-14. doi: $10.1016 /$ j.ijpsycho.2005.08.003
Han, L., Liu, Y., Zhang, D., Jin, Y., and Luo, Y. (2013). Low-arousal speech noise improves performance in n-back task: an ERP study. PLoS ONE 8:e76261. doi: 10.1371/journal.pone.0076261

Handy, T. C., and Mangun, G. R. (2000). Attention and spatial selection: Electrophysiological evidence for modulation by perceptual load. Percept Psychophys. 62, 175-186. doi: 10.3758/BF03212070

Harborne, G. C., Watson, F. L., Healy, D. T., and Groves, L. (1996). The effects of sub-anaesthetic doses of ketamine on memory, cognitive performance and subjective experience in healthy volunteers. J. Psychopharmacol. 10, 134-140. doi: $10.1177 / 026988119601000208$

Harmony, T., Bernal, J., Fernández, T., Silva-Pereyra, J., Fernández-Bouzas, A., Marosi, E., et al. (2000). Primary task demands modulate P3a amplitude. Cogn. Brain Res. 9, 53-60. doi: 10.1016/S0926-6410(99)00044-0

Heekeren, K., Daumann, J., Neukirch, A., Stock, C., Kawohl, W., Norra, C., et al. (2008). Mismatch negativity generation in the human 5HT2A agonist and NMDA antagonist model of psychosis. Psychopharmacology 199, 77-88. doi: 10.1007/s00213-008-1129-4

Hetem, L. A., Danion, J. M., Diemunsch, P., and Brandt, C. (2000). Effect of a subanesthetic dose of ketamine on memory and conscious awareness healthy volunteers. Psychopharmacology 152, 283-288. doi: 10.1007/s002130000511

Hillyard, S. A., Hink, R. F., Schwent, V. L., and Picton, T. W. (1973). Electrical signs of selective attention in the human brain. Science 182, 177-180. doi: $10.1126 /$ science.182.4108.177

Holliday, W. B., Gurnsey, K., Sweet, R. A., and Teichert, T. (2017). A putative electrophysiological biomarker of auditory sensory memory encoding is sensitive to pharmacological alterations of excitatory/inhibitory balance in male macaque monkeys. J. Psychiatry Neurosci. 43:170093. doi: 10.1503/jpn. 170093

Hopfinger, J. B., and Mangun, G. R. (1998). Reflexive attention modulates processing of visual stimuli in human extrastriate cortex. Psychol. Sci. 9, 441-447. doi: 10.1111/1467-9280.00083

Horváth, J., Winkler, I., and Bendixen, A. (2008). Do N1/MMN, P3a, and RON form a strongly coupled chain reflecting the three stages of auditory distraction? Biol. Psychol. 79, 139-147. doi: 10.1016/j.biopsycho.2008.04.001

Isreal, J. B., Wickens, C. D., Chesney, G. L., and Donchin, E. (1980). The event-related brain potential as an index of display-monitoring workload. Hum. Factors J. Hum. Factors Ergon Soc. 22, 211-224. doi: 10.1177/001872088002200210

Javitt, D. C. (2010). Glutamatergic theories of schizophrenia. Isr. J. Psychiatry Relat. Sci. 47, 4-16.

Javitt, D. C., Grochowski, S., Shelleya, M., and Ritter, W. (1998). Impaired mismatch negativity (MMN) generation in schizophrenia as a function of stimulus deviance, probability, and interstimulus/interdeviant interval. Electroencephalogr. Clin. Neurophysiol. 108, 143-153.

Javitt, D. C., Jayachandra, M., Lindsley, R. W., Specht, C. M., and Schroeder, C. E. (2000). Schizophrenia-like deficits in auditory P1 and N1 refractoriness induced by the psychomimetic agent phencyclidine (PCP). Clin. Neurophysiol. 111, 833-836. doi: 10.1016/S1388-2457(99)00313-2

Jiang, C., and Rau, P. P. (2017). Working memory performance impaired after exposure to acute social stress: The evidence comes from ERPs. Neurosci. Lett. 658, 137-141. doi: 10.1016/j.neulet.2017.08.054

Kantrowitz, J., and Javitt, D. C. (2012). Glutamatergic transmission in schizophrenia: from basic research to clinical practice. Curr. Opin. Psychiatry 25, 96-102. doi: 10.1097/YCO.0b013e32835035b2

Kantrowitz, J. T., Epstein, M. L., Lee, M., Lehrfeld, N., Nolan, K. A., Shope, C., et al. (2018). Improvement in mismatch negativity generation during d-serine treatment in schizophrenia: Correlation with symptoms. Schizophr. Res. 191, 70-79. doi: 10.1016/j.schres.2017.02.027

Katayama, J., and Polich, J. (1998). Stimulus context determines P3a and P3b. Psychophysiology 35, 23-33. doi: 10.1111/1469-8986.3510023

Knott, V. J., Millar, A. M., McIntosh, J. F., Shah, D. K., Fisher, D. J., Blais, C. M., et al. (2011). Separate and combined effects of low dose ketamine and nicotine on behavioural and neural correlates of sustained attention. Biol. Psychol. 88, 83-93. doi: 10.1016/j.biopsycho.2011.06.012

Kok, A. (2001). On the utility of P3 amplitude as a measure of processing capacity. Psychophysiology 38, 557-577. doi: 10.1017/S0048577201990559

Kort, N. S., Ford, J. M., Roach, B. J., Gunduz-Bruce, H., Krystal, J. H., Jaeger, J., et al. (2017). Role of N-Methyl-D-Aspartate receptors in action-based 
predictive coding deficits in schizophrenia. Biol. Psychiatry 81, 514-524. doi: 10.1016/j.biopsych.2016.06.019

Koychev, I., El-Deredy, W., Haenschel, C., and Deakin, J. F. W. (2010). Visual information processing deficits as biomarkers of vulnerability to schizophrenia: an event-related potential study in schizotypy. Neuropsychologia 48, 2205-2214. doi: 10.1016/j.neuropsychologia.2010.04.014

Koychev, I., William Deakin, J. F., El-Deredy, W., and Haenschel, C. (2017). Effects of acute ketamine infusion on visual working memory: eventrelated potentials. Biol. Psychiatry Cogn. Neurosci. Neuroimaging 2, 253-262. doi: 10.1016/j.bpsc.2016.09.008

Kramer, A. F., Trejo, L. J., and Humphrey, D. (1995). Assessment of mental workload with task-irrelevant auditory probes. Biol. Psychol. 40, 83-100. doi: 10.1016/0301-0511(95)05108-2

Kreitschmann-Andermahr, I., Rosburg, T., Demme, U., Gaser, E., Nowak, H., and Sauer, H. (2001). Effect of ketamine on the neuromagnetic mismatch field in healthy humans. Brain Res. Cogn. Brain Res. 12, 109-116. doi: 10.1016/S0926-6410(01)00043-X

Krystal, J. H., Karper, L. P., Seibyl, J. P., Freeman, G. K., Delaney, R., Bremner, J. D., et al. (1994). Subanesthetic effects of the noncompetitive NMDA antagonist, ketamine, in humans. psychotomimetic, perceptual, cognitive, and neuroendocrine responses. Arch. Gen. Psychiatry 51, 199-214. doi: 10.1001/archpsyc.1994.03950030035004

Lange, K., and Schnuerch, R. (2014). Challenging perceptual tasks require more attention: the influence of task difficulty on the N1 effect of temporal orienting. Brain Cogn. 84, 153-163. doi: 10.1016/j.bandc.2013.12.001

Lofwall, M. R., Griffiths, R. R., and Mintzer, M. Z. (2006). Cognitive and subjective acute dose effects of intramuscular ketamine in healthy adults. Exp. Clin. Psychopharmacol. 14, 439-449. doi: 10.1037/1064-1297.14.4.439

Lorist, M. M., Snel, J., Kok, A., and Mulder, G. (1994). Influence of caffeine on selective attention in well-rested and fatigued subjects. Psychophysiology 31, 525-534. doi: 10.1111/j.1469-8986.1994.tb02345.x

Lv, J. Y., Wang, T., Qiu, J., Feng, S. H., Tu, S., and Wei, D. T. (2010). The electrophysiological effect of working memory load on involuntary attention in an auditory-visual distraction paradigm: an ERP study. Exp. Brain Res. 205, 81-86. doi: 10.1007/s00221-010-2360-x

Mathalon, D. H., Ahn, K. H., Perry, E. B., Cho, H. S., Roach, B. J., Blais, R. K., et al. (2014). Effects of nicotine on the neurophysiological and behavioral effects of ketamine in humans. Front. Psychiatry 5:3. doi: 10.3389/fpsyt.2014.00003

Matthews, A., Garry, M. I., Martin, F., and Summers, J. (2006). Neural correlates of performance trade-offs and dual-task interference in bimanual coordination: an ERP investigation. Neurosci. Lett. 400, 172-6. doi: 10.1016/j.neulet.2006.02.043

Matthews, A. J., Martin, F. H., Garry, M., and Summers, J. J. (2009). The behavioural and electrophysiological effects of visual task difficulty and bimanual coordination mode during dual-task performance. Exp. Brain Res. 198, 477-487. doi: 10.1007/s00221-009-1943-x

McEvoy, L. K., Pellouchoud, E., Smith, M. E., and Gevins, A. (2001). Neurophysiological signals of working memory in normal aging. Cogn. Brain Res. 11, 363-376. doi: 10.1016/S0926-6410(01)00009-X

Mecklinger, A., Kramer, A. F., and Strayer, D. L. (1992). Event related potentials and EEG components in a semantic memory search task. Psychophysiology 29, 104-119. doi: 10.1111/j.1469-8986.1992.tb02021.x

Mehaffey, L., Seiple, W., and Holopigian, K. (1993). Comparison of P100 and P300 cortical potentials in spatial frequency discrimination. Doc. Ophthalmol. 85, 173-183. doi: 10.1007/BF01371132

Miller, M. W., Rietschel, J. C., McDonald, C. G., and Hatfield, B. D. (2011). A novel approach to the physiological measurement of mental workload. Int. J. Psychophysiol. 80, 75-78. doi: 10.1016/j.ijpsycho.2011.02.003

Molloy, K., Griffiths, T. D., Chait, M., and Lavie, N. (2015). Inattentional deafness: visual load leads to time-specific suppression of auditory evoked responses. J. Neurosci. 35, 16046-16054. doi: 10.1523/JNEUROSCI.2931-15.2015

Morlet, D., Ruby, P., André-Obadia, N., and Fischer, C. (2017). The auditory oddball paradigm revised to improve bedside detection of consciousness in behaviorally unresponsive patients. Psychophysiology 54, 1644-1662. doi: 10.1111 /psyp.12954

Mulert, C., Menzinger, E., Leicht, G., Pogarell, O., and Hegerl, U. (2005). Evidence for a close relationship between conscious effort and anterior cingulate cortex activity. Int. J. Psychophysiol. 56, 65-80. doi: 10.1016/j.ijpsycho.2004.10.002
Mulert, C., Seifert, C., Leicht, G., Kirsch, V., Ertl, M., Karch, S., et al. (2008). Single-trial coupling of EEG and fMRI reveals the involvement of early anterior cingulate cortex activation in effortful decision making. Neuroimage 42, 158-168. doi: 10.1016/j.neuroimage.2008.04.236

Muller-Gass, A., Stelmack, R. M., and Campbell, K. B. (2006). The effect of visual task difficulty and attentional direction on the detection of acoustic change as indexed by the mismatch negativity. Brain Res. 1078, 112-130. doi: 10.1016/j.brainres.2005.12.125

Murck, H., Spitznagel, H., Ploch, M., Seibel, K., and Schaffler, K. (2006). Hypericum extract reverses S-ketamine-induced changes in auditory evoked potentials in humans - Possible implications for the treatment of schizophrenia. Biol. Psychiatry 59, 440-445. doi: 10.1016/j.biopsych.2005.07.008

Musso, F., Brinkmeyer, J., Ecker, D., London, M. K., Thieme, G., Warbrick, T., et al. (2011). Ketamine effects on brain function - Simultaneous fMRI/EEG during a visual oddball task. Neuroimage 58, 508-525. doi: 10.1016/j.neuroimage.2011.06.045

Näätänen, R. (1982). Processing negativity: an evoked-potential reflection of selective attention. Psychol Bull. 92, 605-40. doi: 10.1037/0033-2909.92.3.605

Näätänen, R. (1990). The role of attention in auditory by event-related potentials and other brain measures of cognitive function. Behav. Brain Sci. 13, 201-288. doi: 10.1017/S0140525X00078407

Näätänen, R., Gaillard, A. W., and Mäntysalo, S. (1978). Early selectiveattention effect on evoked potential reinterpreted. Acta Psychol. 42, 313-29. doi: 10.1016/0001-6918(78)90006-9

Näätänen, R., Gaillard, A. W., and Varey, C. A. (1981). Attention effects on auditory EPs as a function of inter-stimulus interval. Biol. Psychol. 13, 173-87. doi: 10.1016/0301-0511(81)90034-X

Näätänen, R., Kujala, T., and Winkler, I. (2011). Auditory processing that leads to conscious perception: a unique window to central auditory processing opened by the mismatch negativity and related responses. Psychophysiology 48, 4-22. doi: 10.1111/j.1469-8986.2010.01114.x

Näätänen, R., and Picton, T. (1987). The N1 wave of the human electric and magnetic response to sound: a review and an analysis of the component structure. Psychophysiology 24, 375-425. doi: 10.1111/j.1469-8986.1987.tb00311.x

Newcomer, J. W., Farber, N. B., and Jevtovic-Todorovic, V. (1999). Ketamine- induced NMDA receptor hypofunction as a model of memory impairment and psychosis. Neuropsychopharmacology 20, 106-118. doi: 10.1016/S0893-133X(98)00067-0

Oranje, B., Gispen-De Wied, C. C., Westenberg, H. G. M., Kemner, C., Verbaten, M. N., and Kahn, R. S. (2009). Haloperidol counteracts the ketamine-induced disruption of processing negativity, but not that of the P300 amplitude. Int. J. Neuropsychopharmacol. 12, 823-832. doi: 10.1017/S1461145708009814

Oranje, B., van Berckel, B. N., Kemner, C., van Ree, J. M., Kahn, R. S., and Verbaten, M. N. (2000). The effects of a sub-anaesthetic dose of ketamine on human selective attention. Neuropsychopharmacology. 22, 293-302. doi: 10.1016/S0893-133X(99)00118-9

Oranje, B., Wied, C. C. G., Verbaten, M. N., and Kahn, R. S. (2002). Modulating sensory gating in healthy volunteers: the effects of ketamine and haloperidol. Biol. Psychiatry 52, 887-895.

Parmentier, F. B. (2014). The cognitive determinants of behavioral distraction by deviant auditory stimuli: a review. Psychol. Res. 78, 321-338. doi: 10.1007/s00426-013-0534-4

Patterson, J. V., Hetrick, W. P., Boutros, N. N., Jin, Y., Sandman, C., Stern, H. et al. (2008). P50 sensory gating ratios in schizophrenics and controls: a review and data analysis. Psychiatry Res. 158, 226-247. doi: 10.1016/j.psychres.2007. 02.009

Polich, J. (1987). Task difficulty, probability, and inter-stimulus interval as determinants of P300 from auditory stimuli. Electroencephalogr. Clin. Neurophysiol. Evoked Potentials 68, 311-320.

Polich, J. (2007). Updating P300: an integrative theory of P3a and P3b. Clin Neurophysiol. 118, 2128-2148. doi: 10.1016/j.clinph.2007.04.019

Polich, J., and Comerchero, M. D. (2003). P3a from visual stimuli: typicality, task, and topography. Brain Topogr. 15, 141-152. doi: 10.1023/A:10226377 32495

Pratt, N., Willoughby, A., and Swick, D. (2011). Effects of working memory load on visual selective attention: behavioral and electrophysiological evidence. Front. Hum. Neurosci. 5:57. doi: 10.3389/fnhum.2011.00057 
Restuccia, D., Della Marca, G., Marra, C., Rubino, M., and Valeriani, M. (2005). Attentional load of the primary task influences the frontal but not the temporal generators of mismatch negativity. Cogn. Brain Res. 25, 891-899. doi: 10.1016/j.cogbrainres.2005.09.023

Ries, A. J., Touryan, J., Ahrens, B., and Connolly, P. (2016). The impact of task demands on fixation-related brain potentials during guided search. PLoS ONE 11:e0157260. doi: 10.1371/journal.pone.0157260

Rosburg, T. (2004). Effects of tone repetition on auditory evoked neuromagnetic fields. Clin. Neurophysiol. 115, 898-905. doi: 10.1016/j.clinph.2003.11.011

Rosburg, T., and Kreitschmann-Andermahr, I. (2016). The effects of ketamine on the mismatch negativity $(\mathrm{MMN})$ in humans - A meta-analysis. Clin. Neurophysiol. 127, 1387-1394. doi: 10.1016/j.clinph.2015.10.062

Rosburg, T., Weigl, M., Thiel, R., and Mager, R. (2018). The event-related potential component $\mathrm{P} 3 \mathrm{a}$ is diminished by identical deviance repetition, but not by non-identical repetitions. Exp. Brain Res. 236, 1519-1530. doi: 10.1007/s00221-018-5237-z

Ruhnau, P., Wetzel, N., Widmann, A., and Schröger, E. (2010). The modulation of auditory novelty processing by working memory load in school age children and adults: A combined behavioral and event-related potential study. BMC Neurosci. 11:126. doi: 10.1186/1471-2202-11-126.

SanMiguel, I., Corral, M.-J., and Escera, C. (2008). When loading working memory reduces distraction : behavioral and electrophysiological evidence from an auditory - visual distraction paradigm. J. Cogn. Neurosci. 20, 1131-1145. doi: 10.1162/jocn.2008.20078

Sawaki, R., and Katayama, J. (2006). Stimulus context determines whether nontarget stimuli are processed as task-relevant or distractor information. Clin. Neurophysiol. 117, 2532-2539. doi: 10.1016/j.clinph.2006.06.755

Scharinger, C., Soutschek, A., Schubert, T., and Gerjets, P. (2015). When flanker meets the n-back: What, E. E. G., and pupil dilation data reveal about the interplay between the two central-executive working memory functions inhibition and updating. Psychophysiology 52, 1293-1304. doi: $10.1111 /$ psyp. 12500

Scharinger, C., Soutschek, A., Schubert, T., and Gerjets, P. (2017). Comparison of the working memory load in n-back and working memory span tasks by means of EEG frequency band power and p300 amplitude. Front. Hum. Neurosci. 11:6. doi: 10.3389/fnhum.2017.00006

Scheffers, M. K., Johnson, R., and Ruchkin, D. S. (1991). P300 in patients with unilateral temporal lobectomies: the effects of reduced stimulus quality. Psychophysiology 28, 274-284. doi: 10.1111/j.1469-8986.1991.tb02194.x

Schmidt, A., Bachmann, R., Kometer, M., Csomor, P. A., Stephan, K. E., Seifritz, E., et al. (2012). Mismatch negativity encoding of prediction errors predicts S-ketamine-induced cognitive impairments. Neuropsychopharmacology 37, 865-875. doi: 10.1038/npp.2011.261

Schmidt, A., Kometer, M., Bachmann, R., Seifritz, E., and Vollenweider, F. (2013). The NMDA antagonist ketamine and the 5-HT agonist psilocybin produce dissociable effects on structural encoding of emotional face expressions. Psychopharmacology 225, 227-239. doi: 10.1007/s00213-012-2811-0

Schubert, M., Johannes, S., Koch, M., Wieringa, B. M., Dengler, R., and Munte, T. F. (1998). Differential effects of two motor tasks on ERPs in an auditory classification task: evidence of shared cognitive resources. Neurosci. Res. 30, 125-134. doi: 10.1016/S0168-0102(97)00115-6

Schwent, V. L., Hillyard, S. A., and Galambos, R. (1976). Selective attention and the auditory vertex potential. Effects of signal intensity and masking noise. Electroencephalogr. Clin. Neurophysiol. 40, 615-622.

Schwertner, A., Zortea, M., Torres, F. V., and Caumo, W. (2018). Effects of subanesthetic ketamine administration on visual and auditory event-related potentials (ERP) in humans: a systematic review. Front. Behav. Neurosci. 12:70. doi: 10.3389/fnbeh.2018.00070

Sculthorpe, L. D., Collin, C. A., and Campbell, K. B. (2008). The influence of strongly focused visual attention on the detection of change in an auditory pattern. Brain Res. 1234, 78-86. doi: 10.1016/j.brainres.2008.07.031

Simon, S. S., Tusch, E. S., Holcomb, P. J., and Daffner, K. R. (2016). Increasing working memory load reduces processing of cross-modal task-irrelevant stimuli even after controlling for task difficulty and executive capacity. Front. Hum. Neurosci. 10:380. doi: 10.3389/fnhum.2016.00380

Sugimoto, F., and Katayama, J. (2013). Somatosensory P2 reflects resource allocation in a game task: Assessment with an irrelevant probe technique using electrical probe stimuli to shoulders. Int. J. Psychophysiol. 87, 200-204. doi: 10.1016/j.ijpsycho.2013.01.007

Sugimoto, F., and Katayama, J. (2017). Increased visual task difficulty enhances attentional capture by both visual and auditory distractor stimuli. Brain Res. 1664, 55-62. doi: 10.1016/j.brainres.2017.03.026

Swerdlow, N. R., Bhakta, S. G., and Light, G. A. (2018). Room to move: plasticity in early auditory information processing and auditory learning in schizophrenia revealed by acute pharmacological challenge. Schizophr. Res. 199, 285-291. doi: 10.1016/j.schres.2018.03.037

Takeda, Y., Okuma, T., Kimura, M., Kurata, T., Takenaka, T., and Iwaki, S. (2014). Electrophysiological measurement of interest during walking in a simulated environment. Int. J. Psychophysiol. 93, 363-370. doi: 10.1016/j.ijpsycho.2014.05.012

Taylor, M. J. (2002). Non-spatial attentional effects on P1. Clin. Neurophysiol. 113, 1903-1908. doi: 10.1016/S1388-2457(02)00309-7

Thibaut, F., Boutros, N. N., Jarema, M., Oranje, B., Hasan, A., Daskalakis, Z. J., et al. (2015). Consensus paper of the WFSBP Task Force on Biological Markers: criteria for biomarkers and endophenotypes of schizophrenia part I: Neurophysiol. World J. Biol. Psychiatry 16, 280-290. doi: 10.3109/15622975.2015.1050061

Tobimatsu, S., and Celesia, G. G. (2006). Studies of human visual pathophysiology with visual evoked potentials. Clin. Neurophysiol. 117, 1414-1433. doi: 10.1016/j.clinph.2006.01.004

Tusch, E. S., Alperin, B. R., Ryan, E., Holcomb, P. J., Mohammed, A. H., and Daffner, K. R. (2016). Changes in neural activity underlying working memory after computerized cognitive training in older adults. Front. Aging Neurosci. 8:255. doi: 10.3389/fnagi.2016.00255

Tusch, E. S., Feng, N. C., Holcomb, P. J., and Daffner, K. R. (2017). Taskirrelevant novel sounds have antithetical effects on visual target processing in young and old adults. Front. Aging Neurosci. 9:348. doi: 10.3389/fnagi.2017. 00348

Ulanovsky, N., Las, L., and Nelken, I. (2003). Processing of low-probability sounds by cortical neurons. Nat. Neurosci. 6, 391-398. doi: 10.1038/ nn 1032

Ullsperger, P., Freude, G., and Erdmann, U. (2001). Auditory probe sensitivity to mental workload changes-an event-related potential study. Int. J. Psychophysiol. 40, 201-209. doi: 10.1016/S0167-8760(00)00188-4

Umbricht, D., Alberati, D., Martin-Facklam, M., Borroni, E., Youssef, E. A., Ostland, M., et al. (2014). Effect of bitopertin, a glycine reuptake inhibitor, on negative symptoms of schizophrenia: a randomized, double-blind, proof-of-concept study. JAMA Psychiatry 71, 637-646. doi: 10.1001/jamapsychiatry.2014.163

Umbricht, D., Koller, R., Vollenweider, F. X., and Schmid, L. (2002). Mismatch negativity predicts psychotic experiences induced by NMDA receptor antagonist in healthy volunteers. Biol. Psychiatry 51, 400-406. doi: 10.1016/S0006-3223(01)01242-2

Umbricht, D., Schmid, L., Koller, R., Vollenweider, F. X., Hell, D., and Javitt, D. C. (2000). Ketamine-induced deficits in auditory and visual contextdependent processing in healthy volunteers: implications for models of cognitive deficits in schizophrenia. Arch. Gen. Psychiatry 57, 1139-1147. doi: 10.1001/archpsyc.57.12.1139

van Berckel, B. N., Oranje, B., Van Ree, J. M., Verbaten, M. N., and Kahn, R. S. (1998). The effects of low dose ketamine on sensory gating, neuroendocrine secretion and behavior in healthy human subjects. Psychopharmacology 137, 271-281. doi: 10.1007/s002130050620

Vogel, E. K., and Luck, S. J. (2000). The visual N1 component as an index of a discrimination process. Psychophysiology 37, 190-203. doi: $10.1111 / 1469-8986.3720190$

Vollenweider, F. X., Vontobel, P., Hell, D., and Leenders, K. L. (2000). Effects of (S)-ketamine on striatal dopamine : a [11C]raclopride PET study of a model psychosis in humans. J. Psychiatr. Res. 34, 35-43. doi: 10.1016/S0022-3956(99)00031-X

Watson, T. D., Petrakis, I. L., Edgecombe, J., Perrino, A., Krystal, J. H., and Mathalon, D. H. (2009). Modulation of the cortical processing of novel and target stimuli by drugs affecting glutamate and GABA neurotransmission. Int. J. Neuropsychopharmacol. 12, 357-370. doi: 10.1017/S14611457080 09334 
Watter, S., Geffen, G. M., and Geffen, L. B. (2001). The n-back as a dual task: P300 morphology under divided attention. Psychophysiology 38, 998-1003. doi: 10.1111/1469-8986.3860998

Wickens, C., Kramer, A., Vanasse, L., and Donchin, E. (1983). Performance of concurrent tasks: a psychophysiological analysis of the reciprocity of information-processing resources. Science 221, 1080-1082. doi: $10.1126 /$ science. 6879207

Wilkinson, R. T., and Morlock, H. C. (1967). Auditory evoked response and reaction time. Electroencephalogr. Clin. Neurophysiol. 23, 50-56. doi: 10.1016/0013-4694(67)90140-X

Wintink, A. J., Segalowitz, S. J., and Cudmore, L. J. (2001). Task complexity and habituation effects on frontal P300 topography. Brain Cogn. 46, 307-311. doi: 10.1016/S0278-2626(01)80090-7

Woldorff, M. G., and Hillyard, S. A. (1991). Modulation of early auditory processing during selective listening to rapidly presented tones. Electroencephalogr. Cin. Neurophysiol. 79, 170-91. doi: 10.1016/0013-4694(91)90136-R

Wronka, E., Kaiser, J., and Coenen, A. M. L. (2008). The auditory P3 from passive and active three-stimulus oddball paradigm. Acta Neurobiol. Exp. 68, 362-372.

Yucel, G., Petty, C., McCarthy, G., and Belger, A. (2005). Visual task complexity modulates the brain's response to unattended auditory novelty. Neuroreport 16, 1031-1036.
Yurgil, K. A., and Golob, E. J. (2013). Cortical potentials in an auditory oddball task reflect individual differences in working memory capacity. Psychophysiology 50 1263-1274. doi: 10.1111/psyp.12140

Zhang, P., Chen, X., Yuan, P., Zhang, D., and He, S. (2006). The effect of visuospatial attentional load on the processing of irrelevant acoustic distractors. Neuroimage 33, 715-724. doi: 10.1016/j.neuroimage.2006.07.015

Zhang, Q., Yang, X., Yao, L., and Zhao, X. (2017). Working memory load-dependent spatio-temporal activity of single-trial P3 response detected with an adaptive wavelet denoiser. Neuroscience 346, 64-73. doi: 10.1016/j.neuroscience.2017.01.012

Conflict of Interest Statement: The authors declare that the research was conducted in the absence of any commercial or financial relationships that could be construed as a potential conflict of interest.

Copyright $\odot 2018$ Rosburg and Schmidt. This is an open-access article distributed under the terms of the Creative Commons Attribution License (CC BY). The use, distribution or reproduction in other forums is permitted, provided the original author(s) and the copyright owner(s) are credited and that the original publication in this journal is cited, in accordance with accepted academic practice. No use, distribution or reproduction is permitted which does not comply with these terms. 


\section{GLOSSARY}

\section{ERP component}

P3b

Mismatch Negativity (MMN)

P3a

Auditory P1

Auditory N1

Visual P1

Visual N1

Processing negativity (PN)

\section{Description}

Also labeled "P300" and "P3;" huge centro-parietal positivity (peaking 250-500 ms); usually investigated in active oddball experiments; cortical response to stimuli defined as targets; the P3b is presumed to reflect attention and working memory processes (Polich, 2007)

Fronto-central negativity (peaking 100-250 ms); usually investigated in passive oddball experiments; elicited by deviants; quantified by subtracting the ERPs to standard stimuli from the ERPs to deviants; the MMN is presumed to reflect pre-attentive memory-based change-detection mechanisms (Näätänen et al., 2011)

Fronto-central positivity (peaking 250-400 ms); can be investigated in passive and active oddball experiments; elicited by deviant, rare, or novel events; reflecting an unintended attention switch (Näätänen, 1990; Polich, 2007)

Also labeled, "P50;" small, early auditory evoked potential (AEP) component (peaking 40-80 ms) with positive polarity; maximal at fronto-central electrodes; elicited by all auditory stimuli; in psychiatric research primarily investigated in the paired-click experiment ("sensory gating"); reflects sensory processes (Patterson et al., 2008)

Also labeled, "N100;" large AEP component with negative polarity (peaking 70-140 ms) following the auditory P1; maximal at fronto-central electrodes; elicited by all auditory stimuli; can be investigated among others in passive and active oddball experiments, as well as in paired-click experiment; has multiple subcomponents; reflects perceptual processes (Näätänen and Picton, 1987)

Early visually evoked potential (VEP) component (peaking 100 ms); left and right temporo-parietal maxima; elicited by all visual stimuli; strongly modulated by the physical characteristics of the stimuli (Tobimatsu and Celesia, 2006)

VEP component with negative polarity (peaking 140-200 ms) following the visual P1; left and right temporo-parietal maxima; has multiple subcomponents; reflects perceptual and attentional processes (Vogel and Luck, 2000); when elicited by faces, the visual N1 has also been labeled N170 (Bentin et al., 1996)

Fronto-central negativity (peaking 100-300 ms); usually investigated in dichotic listening task (attending to auditory input to one ear while ignoring the input to other ear); quantified by subtracting the ERPs to ignored stimuli from the ERPs to attended stimuli; reflects selective attention (Näätänen, 1990) 